\title{
In Vivo Phage Display to Identify New Human Antibody Fragments Homing to Atherosclerotic Endothelial and Subendothelial Tissues
}

\author{
Kamel Deramchia, ${ }^{* \dagger}$ Marie-Josée Jacobin-Valat, ${ }^{* \dagger}$ \\ Amélie Vallet, ${ }^{\ddagger}$ Hervé Bazin, ${ }^{\S}$ Xavier Santarelli, ${ }^{\ddagger}$ \\ Stéphane Sanchez, ${ }^{*}$ Pierre Dos Santos, ${ }^{\dagger}$ \\ Jean-Michel Franconi, ${ }^{*}$ Stéphane Claverol," \\ Stéphane Bonetto, ${ }^{{ }^{\dagger}}$ and Gisèle Clofent-Sanchez ${ }^{\star \dagger}$ \\ From the Magnetic Resonance Center of Biological Systems, ${ }^{*}$ UMR \\ 5536, National Center for Scientific Research, the Technology \\ Platform for Biomedical Innovation, ${ }^{\dagger}$ the Functional Genomics \\ Platform, " and EA 4135 ENSTBB, ${ }^{*}$ National College of \\ Technology of Biomolecules in Bordeaux, Bordeaux Segalen \\ University, Bordeaux; and Cisbio Bioassays, ${ }^{\circledR}$ Marcel Boiteux \\ Park, Codolet, France
}

In vivo phage display selection is a powerful strategy for directly identifying agents that target the vasculature of normal or diseased tissues in living animals. We describe here a new in vivo biopanning strategy in which a human phage single-chain antibody (scFv) library was injected into high-fat diet-fed $A$ ApoE ${ }^{-/-}$ mice. Extracellular and internalized phage scFvs were selectively recovered from atherosclerotic vascular endothelium and subjacent tissues. After three successive biopanning rounds, a panel of six clones with distinct gene sequences was isolated. Four scFvs produced and purified in soluble form were shown to interact in vitro with a rabbit atheromatous protein extract by time-resolved fluorescence resonance energy transfer and to target the endothelial cell surface and inflamed intima-related regions of rabbit and human tissue sections ex vivo. These new scFvs selected in a mouse model recognized both rabbit and human tissue, underlying the interspecies similarities of the recognized epitopes. By combining immunoprecipitation and mass spectrometry, one of the selected scFvs was shown to recognize carbonic anhydrase II, an up-regulated enzyme involved in resorption of ectopic calcification. These results show that in vivo biopanning selection in hypercholesterolemic animals makes it possible to identify both scFvs homing to atherosclerotic endothelial and subendothelial tissues, and lesion-associated biomarkers. Such scFvs offer promis- ing opportunities in the field of molecular targeting for the treatment of atherosclerosis. (Am J Pathol 2012, 180: 2576-2589; http://dx.doi.org/10.1016/j.ajpath.2012.02.013)

Epidemiological studies have established that elevated plasma levels of apolipoprotein B-containing lipoproteins in humans increase the incidence of coronary heart diseases. ${ }^{1-3}$

Nevertheless, studies on patients developing premature coronary heart disease revealed that $48 \%$ had cholesterol levels below $200 \mathrm{mg} / \mathrm{dL} .{ }^{4}$ In addition, in children with familial hypercholesterolemia and with identical high cholesterol levels, one may have a fatal myocardial infarction at the age of 10 years and the other may survive to 50 years of age. Clearly, additional factors may play a key role in atherogenesis because the rate at which atherosclerosis progresses varies considerably irrespective of the plasma cholesterol level. The disease is likely due, not only to hypercholesterolemia, but also to other local and systemic risk factors, which may be necessary or sufficient to induce atherosclerotic lesions.

Atherosclerosis imaging and therapy strategies entered a new era at the turn of the century. Research efforts have focused on the development of new classes of agents able to act locally and to target the atherogenic components leading to plaque rupture. ${ }^{5,6}$ Progress in understanding the molecular basis of atherosclerosis has opened up horizons for several promising novel targets. ${ }^{7}$ Nevertheless, these have mostly been determined by in vitro approaches. ${ }^{5,6,8-12} \mathrm{New}$ and more efficient targeting agents are in ever-increasing demand for predicting asymptomatic and vulnerable plaques. Major impetus has been given with the development of random in vivo

Supported by Agence Nationale de la Recherche, Program "PhysiqueChimie du Vivant."

Accepted for publication February 14, 2012.

S.B. and G.C.-S. contributed equally as principal investigators.

Address reprint requests to Gisèle Clofent-Sanchez, Ph.D., Centre de Résonance Magnétique des Systèmes Biologiques, UMR 5536, CNRS, Université Bordeaux Ségalen, 33076 Bordeaux, France. E-mail: gisele.clofent-sanchez@rmsb.u-bordeaux2.fr. 
screening technologies. In vivo phage display has been particularly effective for identifying new peptide sequences that revealed homology with natural ligands and were able to recognize known or new targets expressed on the activated endothelial cell surface. ${ }^{13-16}$ Antibodies have received considerable attention in imaging modalities and therapy because they exhibit many advantages over other binders, especially thanks to their specificities and affinities for their antigens and their long plasma half-life. Various murine antibodies have been used in emerging imaging modalities for visualizing the lesions developed in animal models of atherosclerosis. ${ }^{17-20}$ However, the use of fully human antibodies is mandatory for further clinical applications. Not only peptides but also human antibody fragments can be successfully selected in in vivo phage display technology. ${ }^{21-24}$ Here, we use a human single-chain variable fragment (scFv) library and develop a novel in vivo biopanning approach to investigate scFvs able to target the vascular endothelial cell surface proteins and the subendothelial molecular repertoire expressed within atherosclerotic tissues of apolipoprotein $\mathrm{E}$ (ApoE)-deficient mice. This animal model covers most of the features of human atherosclerotic lesions $^{25}$ and is a valuable tool for studying the pathogenesis of atherosclerosis or for developing agents targeting the plaque components in human disease. We report the identification of four scFvs $(\mathrm{H} 2.1, \mathrm{~K} 3.1,18.1$, C3.3) able to recognize rabbit lesional tissue extracts in a direct time-resolved fluorescence resonance energy transfer (TR-FRET) binding assay and to immunostain rabbit and human atherosclerotic tissue sections, thereby underlining the interspecies similarities of targeted epitopes and opening up horizons for translational research. One of the selected scFvs, K3.1, was found to immunoprecipitate carbonic anhydrase isozyme II (CAII), a cytosolic enzyme involved in the dissolution of arterial calcium deposits ${ }^{26}$ and closely associated with macrophage-rich areas.

This in vivo phage display targeting offers highly promising opportunities for the identification of novel lesionspecific ligands and their cognate biomarkers. The selected scFvs may constitute the basis for developing new clinical tools dedicated to molecular imaging and therapy of human atherosclerosis. Moreover, by targeting intratissular molecules, this study expands the field of in vivo phage display applications, which may be applied to other disorders, especially to those with a strong angiogenic component. ${ }^{27}$

\section{Materials and Methods}

\section{Animal Models}

All animal experiments were performed in conformity with the Guide for the Care and Use of Laboratory Animals (NIH Publication No. 85-23, revised 1996) and were accredited by the local ethical committee.

$A p o E^{-\prime-}$ knockout mice and adult male New Zealand White rabbits (NZW), weighing between 2.5 and $3.0 \mathrm{~kg}$, were obtained from Charles Rivers Laboratories (St. Ger- main sur l'Arbresle, France). To promote advanced lesions in $A p o E^{-1-}$ mice, animals were fed a high-fat Western diet [0.3\% (w/w) cholesterol] for 24 weeks.

For 6 to 8 months, one group of rabbits was submitted to a fat atherogenic diet including $0.3 \%(\mathrm{w} / \mathrm{w})$ cholesterol, whereas another group of rabbits was fed a standard laboratory diet and developed only early fatty streak lesions. To promote the development of complicated plaques, rabbits were subjected to an inflammatory surgical injury under anesthesia (intramuscular injection of $20 \mathrm{mg} / \mathrm{kg}$ ketamine and $2 \mathrm{mg} / \mathrm{kg}$ xylazine) 1 to 2 months after beginning the diet. De-endothelialization of the thoracic and abdominal aortic areas was mechanically induced by three inflations and retractions of a 4-F Fogarty balloon catheter (Edwards Lifesciences, Maurepas, France). Rabbit anesthesia was maintained by mask inhalation of $0.25 \%$ to $0.35 \%$ isoflurane, and preventive antithrombotic treatment was given with heparin sodium solution (1000 IU/mL) (Heparin Choay; Sanofi Synthelabo, Paris, France). Analgesia was performed in the presence of $100 \mathrm{mg}$ of aspirin (Injectable Aspegic; Sanofi Synthelabo).

\section{Human Tissue Specimens}

Human carotid arteries were collected from carotid endarterectomy. Human coronary arteries were harvested from patients with end-stage heart failure having undergone heart transplantation. All of the clinical interventions took place at Haut-Lévèque Hospital (Pessac, France). Human tissue specimens were collected after informed consent. They were immediately processed, frozen at $-80^{\circ} \mathrm{C}$, or embedded in paraffin.

\section{Human Phage scFv Library}

A semisynthetic scFv-fragment library designed and constructed by Philibert et $a^{28}$ was used. Briefly, the library was created from a single optimized human scFv framework (13R4 scFv) by introducing amino acid distributions and lengths in the CDR3 the closest to those observed in natural human third complementarity-determining region (CDR3) loops. Two sets of $13 \mathrm{VH}$ (variable heavy chain) libraries with CDR3) loops ranging from 5 to 17 amino acids and $5 \mathrm{VL}$ (variable light chain) libraries $(\kappa+\lambda)$ with CDR3 loops ranging from 9 to 11 amino acids were then screened for their ability to be expressed in frame with fusion protein chloramphenicol acetyltransferase (CAT) enzyme on selective media before PCR assembly. The library was constructed in the PCANTAB6 phagemid vector in fusion with the N-terminus of the minor plll protein. Its diversity is about $1.5 \times 10^{9}$ different variants.

\section{Atheromatous Protein Extraction and Biotinylation}

Aortas from rabbits fed a standard laboratory diet and balloon-injured aortas from hypercholesterolemic rabbits were extracted from the aortic arch to the iliac bifurcation, washed and fractioned to solubilize tissue proteins independently in four different lysis buffers: M-PER (Thermo Fisher Scientific, Brebières, France), T-PER (Thermo 
Fisher Scientific), low stringency lysis buffer [50 mmol/L HEPES (pH 7.4); $137 \mathrm{mmol} / \mathrm{L} \mathrm{NaCl} ; 1 \% \mathrm{NP}-40(\mathrm{v} / \mathrm{v}) ; 2$ mmol/L EDTA; 1 mmol/L phenylmethylsulfonyl fluoride; protease inhibitors cocktail (Roche Diagnostics, Meylan, France)] and high stringency lysis buffer $[50 \mathrm{mmol} / \mathrm{L}$ HEPES (pH 7.4); $150 \mathrm{mmol} / \mathrm{L} \mathrm{NaCl} ; 1 \%$ (v/v) NP-40; 0.5\% (v/v) Triton; 0.5\% sodium deoxycholate; 1 mmol/L EDTA; $1 \mathrm{mmol} / \mathrm{L}$ phenylmethylsulfonyl fluoride; protease inhibitors cocktail). Homogenization was performed by using first a Polytron TP-20 Homogenizer (Kinematica, Lucerne, Switzerland) and then a sonicator ( $3 \times 10$-second pulses at $80 \%$ magnitude). After two centrifugations at 13,000 $\times$ $g$ for 45 minutes at $4^{\circ} \mathrm{C}$ to discard insoluble material from the supernatant, the protein concentration of every soluble extract was determined using the Bradford assay kit according to the manufacturer's instructions (Thermo Fisher Scientific). Proteins from M-PER, T-PER, and high stringency lysis buffer extraction were then dialyzed against low stringency lysis buffer for 16 hours at $4^{\circ} \mathrm{C}$, and $200 \mu \mathrm{g}$ from each protein extraction were biotinylated with three different molar ratios of proteins/biotin-XX SSE (Invitrogen, Eragny sur Oise, France): 1:5, 1:10, and 1:20 in $100 \mathrm{mmol} / \mathrm{L} \mathrm{NaHCO}_{3}(\mathrm{pH}$ 8.3) for 30 minutes at $4^{\circ} \mathrm{C}$. Excess of reactive biotin was then quenched with $100 \mathrm{mmol} / \mathrm{L}$ glycine $\left(\mathrm{pH} \mathrm{7.4)}\right.$ for 10 minutes at $4^{\circ} \mathrm{C}$ and the samples were dialyzed against low stringency lysis buffer for 16 hours at $4^{\circ} \mathrm{C}$.

\section{In Vivo Biopanning in Atherosclerotic Mouse Model}

In vivo phage display selections were performed in $A p o E^{-\prime-}$ mice. Briefly, rabbits received three injections into tail vein of PBS containing $1 \times 10^{12}$ colony-forming units (cfu). After three times 5 minutes circulation, the animal was sacrificed and perfused through the heart with $20 \mathrm{ml}$ of PBS to ensure phage clearance from the blood. The aorta was then extracted from the aortic arch to the iliac bifurcation. The tissue was weighed, gently cut lengthwise, and then rinsed six times with $500 \mu \mathrm{L}$ of cold PBS. Three fractions were recovered: the endothelium cell surface-bound phages (F1 fraction), the intratissular phages (F2 fraction), and the internalized phages (F3 fraction). The endothelium cell surface-bound phages (F1 fraction) were eluted with $100 \mu \mathrm{L}$ of $0.1 \mathrm{~mol} / \mathrm{L}$ glycine$\mathrm{HCl}(\mathrm{pH}$ 2.2) for 8 minutes at room temperature under gentle agitation. After centrifugation at $500 \times g$, eluted phages were collected and immediately neutralized with $15 \mu \mathrm{L}$ of $1 \mathrm{~mol} / \mathrm{L}$ Tris-HCl (pH 9.1) in a clean tube. Meanwhile, the aorta was washed three times with $300 \mu \mathrm{L}$ of cold PBS, and the washing eluates were then pooled in the previous fraction. To access the intratissular phages (F2 fraction), the aorta was dissociated with $900 \mu \mathrm{L}$ of PBS $\left(\mathrm{Ca}^{2+}, \mathrm{Mg}^{2+}\right.$ free) containing $2000 \mathrm{U} / \mathrm{mL}$ of collagenase type $\mathrm{II}$ and adjusted to $1 \mathrm{~mL}$ with $2.5 \%$ trypsin-EDTA for 30 minutes at $37^{\circ} \mathrm{C}$ under agitation. The solubilizate was vigorously vortexed and centrifuged at $1000 \times g$ for 10 minutes at $4^{\circ} \mathrm{C}$. The supernatant was recovered and the pellet washed three times with $400 \mu \mathrm{L}$ of PBS $\left(\mathrm{Ca}^{2+}\right.$, $\mathrm{Mg}^{2+}$ free). In addition, $250 \mu \mathrm{L}$ of $0.1 \mathrm{~mol} / \mathrm{L}$ glycine- $\mathrm{HCl}$
$(\mathrm{pH}$ 2.2) were added to the cell homogenate and incubated for 8 minutes at room temperature under gentle agitation. After centrifugation, eluted phages were collected, neutralized in a clean tube, and then pooled to the washing eluate. Three supplementary cell washings were then performed with $250 \mu \mathrm{L}$ of PBS. To access the internalized phages (F3 fraction), the homogenate was incubated with $500 \mu \mathrm{L}$ of $100 \mathrm{mmol} / \mathrm{L}$ triethylamine $(\mathrm{pH}$ 11) for 5 minutes at room temperature by vigorous vortexing. Neutralization was then done by addition of $250 \mu \mathrm{L}$ of 1 $\mathrm{mol} / \mathrm{L}$ Tris- $\mathrm{HCl}(\mathrm{pH}$ 7.4). After centrifugation at $1000 \times g$ for 10 minutes, the supernatant was collected and the pellet was washed twice more with $500 \mu \mathrm{L}$ of PBS. Phage fractions were separately rescued by infection of $25 \mathrm{~mL}$ of $2 \times$ TY medium containing XL1-Blue Escherichia coli host (Stratagene, La Jolla, CA) in log-growth phase. The phage libraries were then produced following superinfection with M13KO7 helper phage (Invitrogen, Cergy-Pontoise, France) and phages purified from the supernatant culture. Two additional rounds of selection and amplification in subsequent mice were then performed with $1 \times$ $10^{11}$ and $1 \times 10^{10} \mathrm{cfu}$, respectively. Plated bacterial clones from the second and third rounds of biopanning were randomly picked for nucleotide sequence analysis (MilleGen, Toulouse, France) by using the LMB3 primer (sequence, 5'-CAGGAAACAGCTATGAC-3') corresponding to the pCANTAB6 phagemid sequence downstream of the ScFv insert. Sequence translation, comparison, and alignment were done using IMGT/N-QUEST database (http://imgt.org/IMGT_vquest/share/texte, last accessed February 23, 2012).

\section{Soluble scFv Production from Bacterial Culture}

Selected XL1-Blue clones cultured for 5 hours in $500 \mu \mathrm{L}$ of $2 \times$ TY Amp (Ampicillin; $100 \mu \mathrm{g} / \mathrm{mL}$ )/glucose [2\% (w/v)] in $2 \mathrm{~mL}$ of Masterblock (Greiner Bio-One, Courtaboeuf, France) were superinfected with M13KO7 helper phage for 45 minutes. After centrifugation and removal of the supernatant, pellets were resuspended in $1 \mathrm{~mL}$ of $2 \times$ TY Amp (100 $\mu \mathrm{g} / \mathrm{mL}$ )/Kana (kanamycin sulfate; $50 \mu \mathrm{g} / \mathrm{mL}$ ), and an aliquot of each culture was spread onto $2 \times$ TY Amp/Kana agar plates. Isolated bacterial clones were then incubated for 16 hours in $500 \mu \mathrm{L}$ of $2 \times$ TY Amp/ Kana at $25^{\circ} \mathrm{C}$ to induce phage production. After two successive centrifugations, $1 \mu \mathrm{L}$ of phage-containing supernatant was used to infect $20 \mu \mathrm{L}$ of HB2151 E. coli host in log-growth phase. After 45 minutes, bacteria were plated onto $2 \times$ TY Amp (100 $\mu \mathrm{g} / \mathrm{mL}) / \mathrm{glucose}[2 \%(\mathrm{w} / \mathrm{v})$ ] and incubated for 16 hours at $30^{\circ} \mathrm{C}$. Selected HB2151 clones were then cultured in $2 \times$ TY Amp $(100 \mu \mathrm{g} / \mathrm{mL}) /$ sucrose $(0.4 \mathrm{~mol} / \mathrm{L})$ until they reached the log-growth phase. After spinning, the scFv production from the bacterial pellet was induced in $50 \mathrm{~mL}$ of $2 \times$ TY Amp (100 $\mu \mathrm{g} / \mathrm{mL}$ )/IPTG (isopropyl- $\beta$-D-thio-galactoside) (200 $\mathrm{mmol} / \mathrm{L}$ ) for 16 hours at $25^{\circ} \mathrm{C}$.

\section{scFv Purification by Nickel-Affinity Chromatography}

Fifty $\mathrm{mL}$ of HB2151 cell culture were pelleted by centrifugation and the pellet resuspended in 1:10 (v/v) of ice- 
cold osmotic shock buffer [1 mol/L Tris- $\mathrm{HCl}(\mathrm{pH} 8), 1$ $\mathrm{mg} / \mathrm{mL}$ lysozyme, $1 \mathrm{mmol} / \mathrm{L}$ phenylmethylsulfonyl fluoride, protease inhibitors cocktail (Roche Diagnostics)] for 1 hour at $4^{\circ} \mathrm{C}$ on a rotary shaker. Bacterial lysis was then performed by two sonication cycles of $3 \times 10$-second pulses at $80 \%$ magnitude. After centrifugation at $20,000 \times$ $g$ for 30 minutes at $4^{\circ} \mathrm{C}$ to remove the insoluble material, 6 His-tagged scFvs were purified by immobilized metal affinity chromatography using Ni-NTA resins (Pierce, Bezons, France $)^{21}$ and monitored by the Biopilot Chromatographic System (Amersham Biosciences, Saclay, France). Briefly, after equilibration of the column with running buffer $[20 \mathrm{mmol} / \mathrm{L}$ Tris- $\mathrm{HCl}(\mathrm{pH}$ 7.0)] and sample loading, a two-step elution was performed. The first was achieved in the presence of $25 \mathrm{mmol} / \mathrm{L}$ imidazole $(\mathrm{pH}$ 7.0 ) to remove unspecific binding on nickel column, and the second with $250 \mathrm{mmol} / \mathrm{L}$ imidazole $(\mathrm{pH}$ 7.0) was done to elute nickel-bound scFvs into four to five $1-\mathrm{mL}$ fractions. Each recovered fraction was then evaluated for its protein content by absorption at $280 \mathrm{~nm}$ and dialyzed against PBS for 16 hours at $4^{\circ} \mathrm{C}$.

\section{HTRF Inhibition Sandwich Assay for a Qualitative Analysis of Nickel-Purified scFvs}

Nickel-purified scFv fractions were tested for their ability to inhibit homogeneous time-resolved fluorescence (HTRF; Cisbio Bioassays, Codolet, France) sandwich emission signal of biotin-c-myc peptide. This assay makes it possible to determine the minimal amount of scFvs necessary to perform the TR-FRET assay. The reaction was set up in 96-halfwell black plates (Greiner) and in $100 \mu \mathrm{L}$ of reaction volume containing $50 \mu \mathrm{L}$ of reaction buffer [100 mmol/L phosphate buffer ( $\mathrm{pH} 7$ ); $400 \mathrm{mmol} / \mathrm{L} \mathrm{KF}$ buffer; $0.1 \%$ bovine serum albumin (BSA)], $0.4 \mathrm{nmol} / \mathrm{L}$ of anti-c-myc-(Eu)K (Cisbio Bioassays), $5 \mu \mathrm{L}$ of scFv (final concentration between 5 and $170 \mathrm{nmol} / \mathrm{L}$ according to the clone), $1.25 \mathrm{nmol} / \mathrm{L}$ of streptavidin-XL665 (Cisbio Bioassays), and $5 \mathrm{nmol} / \mathrm{L}$ of biotin-c-myc peptide (Cisbio Bioassays). Fluorescence emission was measured on a 24-hour time course after incubation at $4^{\circ} \mathrm{C}$. The percent Delta $\mathrm{F}$ values were normalized using the competitor-free wells percent Delta $\mathrm{F}$ values as the maximal activation (taken as $100 \%)$.

The FRET measurements were expressed as the ratio of the emission intensity at $665 \mathrm{~nm}$ to that at $620 \mathrm{~nm} \times$ 10,000. The normalized FRET signals were expressed as Delta $F(\%)=\left(\right.$ Ratio $_{\text {assay }}-$ Ratio $\left._{\text {Blank }}\right) /$ Ratio $_{\text {Blank. The }}$. The blank values were determined in the absence of both biotinylated c-myc peptide and scFvs.

\section{TR-FRET scFv Binding Assays}

Binding assays between scFvs and atheromatous protein extracts were assessed by direct TR-FRET. Black Fluotrac 600 microplate (Greiner) was coated with $10 \mu \mathrm{L}$ of scFv (final concentration between 3 and $10 \mu \mathrm{g} / \mathrm{mL}$ according to the clone) in $0.1 \mathrm{~mol} / \mathrm{L} \mathrm{NaHCO}$ ( $\mathrm{pH} \mathrm{8.6)}$ for 16 hours at $4^{\circ} \mathrm{C}$. Subsequently, plates were blocked for 3 hours at $4^{\circ} \mathrm{C}$ using $1 \% \mathrm{BSA}(\mathrm{w} / \mathrm{v})$ in PBS solution. Follow- ing washing in PBS, $30 \mu \mathrm{g} / \mathrm{mL}$ of biotinylated atheromatous protein extract in 1\% BSA/PBS was incubated for 16 hours at $4^{\circ} \mathrm{C}$. After washing in PBS, $50 \mu \mathrm{L}$ of reaction buffer [100 mmol/L phosphate buffer (pH 7); $400 \mathrm{mmol} / \mathrm{L}$ KF buffer; $0.1 \% \mathrm{BSA}$ ], $4 \mathrm{nmol} / \mathrm{L}$ of anti c-myc-(Eu)K (Cisbio Bioassays) and $4 \mathrm{nmol} / \mathrm{L}$ of streptavidin-XL665 (Cisbio Bioassays) were incubated in a final volume of 100 $\mu \mathrm{L}$. FRET signal emission was measured and monitored with an Infinite F500 reader (Tecan, Lyon, France) on a 40-hour time course. The percent Delta F values reported the intensity of the direct binding between scFvs and protein extract.

Inhibition assays of the direct TR-FRET binding signal were performed after 16 hours of incubation at $4^{\circ} \mathrm{C}$ in the presence of 2.5-, 5- and 6-fold excess of unlabeled protein extract from atherogenic animals submitted to a 6-to8-month high-fat diet and 6-fold excess of protein extract from animals fed a standard laboratory diet. The percent Delta $F$ values in the presence of unlabeled proteins were normalized relative to the percent Delta $F$ values in the absence of unlabeled proteins (taken as 100\%).

The FRET measurements were expressed as explained above. For direct and inhibition binding assays, the blank values were obtained from signals generated in the absence of scFvs coating.

\section{ScFv Immunohistochemical Analysis on Rabbit and Human Sections}

Paraffin-embedded sections were prepared from rabbit and human arterial tissues. Briefly, sections $10 \mu \mathrm{m}$ thick were deparaffinized and rehydrated before neutralizing endogenous peroxidase activity with $3 \% \mathrm{H}_{2} \mathrm{O}_{2} / \mathrm{H}_{2} \mathrm{O}$ for 5 minutes. Nonspecific binding was then blocked with $4 \%$ $(w / v)$ BSA in PBS solution for 30 minutes at $20^{\circ} \mathrm{C}$. Positive SCFv fractions in direct TR-FRET binding assay were diluted in 2\% BSA/PBS at final concentrations between 2 and $16.5 \mu \mathrm{g} / \mathrm{mL}$ according to the clone production and incubated on tissue sections for 16 hours at $4^{\circ} \mathrm{C}$. Following washings in PBS, a mix of 1:250 anti-c-myc (Miltenyi Biotec, Paris, France) and 1:250 anti-6His (Roche Diagnostics) monoclonal antibodies (mAbs) in $2 \%$ BSA/PBS were applied to the sections for 3 hours at $20^{\circ} \mathrm{C}$. After washings, the sections were incubated with 1:500 horseradish peroxidase (HRP)-conjugated anti-mouse IgG (Immunotech, Marseille, France) for 1 hour at $20^{\circ} \mathrm{C}$. The binding of secondary antibody was detected with a diaminobenzidine substrate kit (Vectastain $\mathrm{ABC}$ kit reagent; Vector Laboratories, Peterborough, UK), which yielded a yellow-brown color reaction. After washings, the sections were dehydrated and mounted in DPX medium (Labonord, Templemar, France).

\section{scFv Competitive Binding Assay on Rabbit Atherosclerotic Aorta Sections}

Specificity of $\mathrm{H} 2.1 \mathrm{scFv}$ binding on tissue sections was also assessed by a competitive binding assay to inhibit the signal generated by the biotinylated form of $\mathrm{H} 2.1$ scFv. Two hundred micrograms of scFv were biotinylated 
according to a molar ratio protein/biotin-XX SSE of 1:10 as described in the previous section. Fifty micrograms of biotin-H2.1 scFv were then incubated on atherosclerotic NZW rabbit sections with or without a four-fold excess of unlabeled $\mathrm{H} 2.1 \mathrm{scFv}$ in $2 \% \mathrm{BSA} / \mathrm{PBS}$ for 16 hours at $4^{\circ} \mathrm{C}$. Following washings, biotinylated ScFv binding was detected using $5 \mu \mathrm{g} / \mathrm{mL}$ of streptavidin-peroxidase conjugate (Vector Laboratories) and diaminobenzidine substrate (Vector Laboratories).

\section{Target Immunoprecipitation and Identification by Mass Spectrometry Analysis}

Nickel-coated superparamagnetic beads (Ademtech, Pessac, France) were pre-washed three times with 500 $\mu \mathrm{L}$ of washing buffer [20 mmol/L Tris $(\mathrm{pH} 7) ; 500 \mathrm{mmol} / \mathrm{L}$ $\mathrm{NaCl}]$ and then incubated for 1 hour with $1 \mathrm{mg}$ of rabbit atheromatous proteins solubilized in low stringency lysis buffer to remove nonspecific binding proteins. The supernatant free of nonspecific binding proteins was recovered and incubated with $10 \mu \mathrm{g}$ of purified K3.1 scFv or of an irrelevant scFv for 16 hours at $4^{\circ} \mathrm{C}$ under rotation. The next day, $20 \mu \mathrm{L}$ of clean pre-washed superparamagnetic beads were added and incubated for a further 1 hour at $20^{\circ} \mathrm{C}$. After three washings with $500 \mu \mathrm{L}$ of binding buffer, the immunoprecipitated complexes were eluted with $2 \times$ $30 \mu \mathrm{L}$ of elution buffer [20 mmol/L Tris- $\mathrm{HCl}(\mathrm{pH} 7.5) ; 500$ $\mathrm{mmol} / \mathrm{L} \mathrm{NaCl} ; 100 \mathrm{mmol} / \mathrm{L}$ imidazole]. The protein complexes were then separated using 10\% SDS-PAGE under reducing conditions. The band was excised and submitted to trypsin digestion, followed by liquid chromatography-tandem mass spectrometry analysis as described. ${ }^{21}$

\section{ELISA Binding Assay on Human CA-II}

Ninety-six-well enzyme-linked immunosorbent assay (ELISA) microtiter plates (Greiner) were coated overnight at $4^{\circ} \mathrm{C}$ with $100 \mu \mathrm{L}$ of human recombinant carbonic anhydrase II (Sigma-Aldrich, St. Louis, MO) at a final concentration of $10 \mu \mathrm{g} / \mathrm{mL}$, or bovine serum albumin at 50 $\mu \mathrm{g} / \mathrm{mL}$ in carbonate buffer $\left[50 \mathrm{mmol} / \mathrm{L} \mathrm{NaHCO}{ }_{3} / \mathrm{Na}_{2} \mathrm{CO}_{3}\right.$ $(\mathrm{pH}$ 9.6)]. All further reactions were performed at room temperature. Following three washing steps with PBSTween 20 (0.5\% Tween 20), $100 \mu \mathrm{L}$ of purified K3.1 scFv at $10 \mu \mathrm{g} / \mathrm{mL}$ were added to each well. After a 2-hour incubation and five washing steps, bound scFv was labeled with a mix of HRP-conjugated anti-c-myc (diluted 1:1000; Miltenyi Biotech) and anti-6His (diluted 1:500; Roche Diagnostics) mAbs. After 1-hour incubation and washing steps, color was developed with $100 \mu \mathrm{L}$ of 3,3',5,5'-tetramethylbenzidine (TMB) liquid substrate system for ELISA (Sigma-Aldrich), and the absorbance was read at $450 \mathrm{~nm}$ with an Infinite F500 reader (Tecan).

\section{Results}

\section{In Vivo Phage scFv Selection}

To select the human phage scFvs able to home to atherosclerotic plaques from the highly diverse human anti- body library, we used an $A p o E^{-\prime-}$ mouse model that develops advanced lesions mimicking the pathophysiological aspects of coronary artery disease observed in humans. ${ }^{25,29}$ For each biopanning round, three successive injections of five-minute circulation time each were performed to promote the chance for phage scFvs of interest to reach and bind targets in the affected sections without being adsorbed nonspecifically on the luminal surface of vascular endothelium cells, and to avoid their clearance from the blood by the reticuloendothelial system (Figure 1). ${ }^{30}$ Furthermore, we reasoned that during the in vivo selection, a subtractive procedure of the library takes place naturally at the unaffected sites.

To have access both to the endothelial cell surface binding phages and to the extravasated and internalized phages, we recovered three independent fractions from aortic tissue (Figure 1). From the second round of selection, the number of recovered cfu from affected tissue markedly increased compared to the first round (Figure 2). The enrichments of selected phages after the third round of biopanning for $\mathrm{F} 1, \mathrm{~F} 2$, and $\mathrm{F} 3$ fractions were respectively 100-, 10-, and 5-fold higher than those recovered from the first round of selection, underlining the probable selection of specific phages against endothelial and subendothelial targets (Table 1). Following the last two rounds of selection, the random sequencing of 150 clones (around 50 from each fraction) revealed three overrepresented amino acid sequences, representing for two of them (H2.1 and C3.3) 10\%, and for the third one

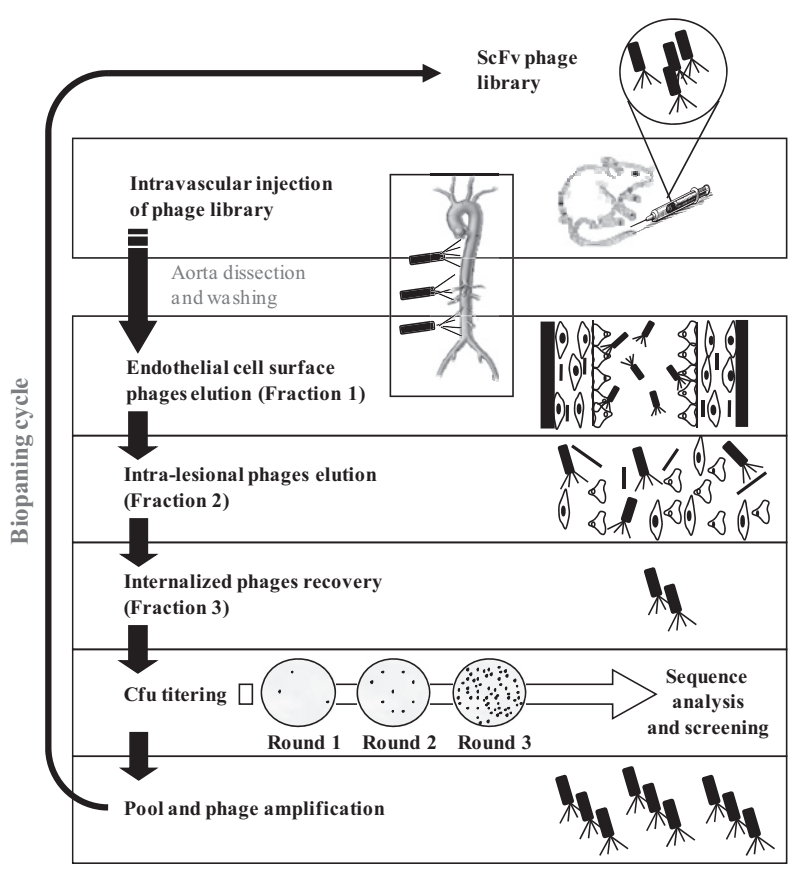

Figure 1. In vivo selection protocol scheme. The $\mathrm{ScFv}$ phage library was intravenously injected into the $A \mathrm{poE}^{-1-}$ mouse model and allowed to circulate for three times 5 minutes. The aorta was then removed, and unbound phages were washed out. Sequential recovery of bound phages was performed from the vascular surface (Fraction 1), subjacent tissue (Fraction 2), and in-cell compartment (Fraction 3). A sample from each fraction was used to generate a new selected library for the next round of biopanning. This process was repeated three times, with random scFv clones sequenced from the second and third rounds and selected for future screening. 


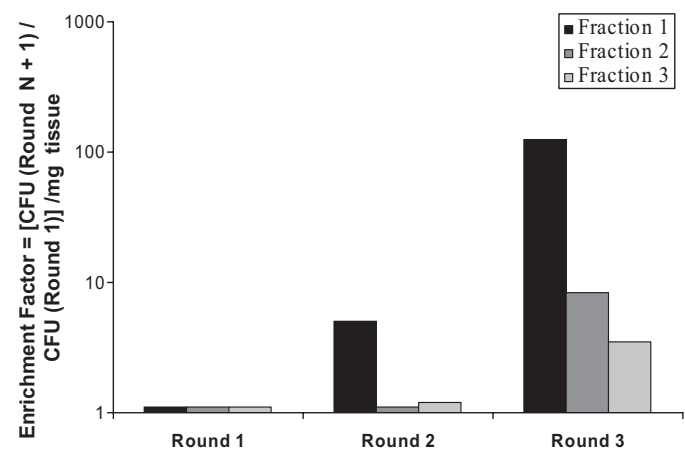

Figure 2. Phage enrichment after three rounds of in vivo biopanning. The number of phages recovered ( $\mathrm{cfu}$ ) from round $\mathrm{n}+1$ was determined relative to the number of cfu obtained from the round 1 per mg of tissue. Fractions 1,2 , and 3 correspond to phages rescued from the vascular surface, subjacent tissue, or in-cell compartment, respectively.

(K3.1) $8 \%$, of the sequenced clones in the screen. Three other amino acid sequences that appeared more than once were also reported (Table 1). None of the scFv bearing these sequences was detected in the clones from the second round of biopanning, suggesting that the in vivo selection pressure was too low to select scFvs with similar sequences from the first two biopanning rounds. Sequence analysis of these six scFvs using the IMGT/NQUEST database revealed six unique sequences whose third complementarity-determining region of antibody heavy chains $(\mathrm{CDRH} 3)$ and third complementarity-determining region of antibody light chains (CDRL3) loops were of variable amino acid composition. Regarding the CDR lengths, the three dominant clones $(\mathrm{H} 2.1, \mathrm{C} 3.3$, and K3.1) showed a similarity both in CDRH3 length (13 residues) and CDRL3 length (10 residues), which represented the fifth representativity of $\mathrm{CDRH} 3$ in the original library and the first and the third of CDR3 $L \kappa$ and CDR3 $L \lambda$, respectively. ${ }^{28}$ The other clones displayed more variable $\mathrm{CDRH} 3$ lengths, whereas the CDRL3 loops systematically comprised 9 amino acids. Among the three dominant clones, H2.1 scFv was mostly found in the F2 fraction, the C3.3 scFv clone was not detected in the F3 fraction, and K3.1 scFv was equally distributed between all of the fractions. Since the number of recovered identical clones in each fraction was low and because this number could increase between two successive fractions (for instance, the H2.1 sequence between fractions F1 and F2 in Table 1), cross-contaminations between fractions could be considered as minimal.

\section{scFv Purification and Qualitative Analysis by HTRF}

To gain access to higher concentrations of antibody fragments, the six scFvs were produced in soluble form using a nonsuppressor $E$. coli strain and were purified from the induced bacterial lysates by nickel chromatography affinity (Figure 3A). Lane 2 shows the SDS-PAGE profile of $\mathrm{H} 2.1 \mathrm{scFv}$ purification and illustrates the purity of the ScFv preparation. To estimate the amount of purified scFvs and test the feasibility of detecting their interactions with atheromatous protein extracts, a highly sensitive binding assay was developed based on HTRF technology. In this assay, the scFvs were investigated for their ability to inhibit the positive HTRF sandwich signal generated by a biotinylated c-myc peptide (Figure 3B). In the absence of competitor, the positive sandwich signal was taken to be $100 \%$. All of the fractions recovered after scFv purification were incubated with the biotin-c-myc peptide, and the time course of competition was measured for 24 hours. The results showed that the highest concentrated fraction from each scFv was able to compete for the c-myc tag by inhibiting the signal by $50 \%$ to $95 \%$ after 16 hours of incubation according to the purified clones. In these assays, final concentrations of scFvs were estimated to be between 5 and $170 \mathrm{nmol} / \mathrm{L}$ according to the clone production and purification.

This set of experiments was designed to estimate the threshold of purified scFvs subsequently needed in a direct TR-FRET screening assay for detecting their interactions with atheromatous protein extracts.

\section{TR-FRET Binding Assay between scFvs and Rabbit Atheromatous Protein Extracts}

Given the limitations of the classic screening approaches for soluble tissue extracts or cell cultures, which are both time- and material-consuming, we set up a very sensitive TR-FRET screening method, ${ }^{31,32}$ based on the direct binding between purified scFvs and atherosclerotic tissue lysate (Figure 4). FRET signals require the close vicinity of two fluorophores, each recognizing one binding partner, which greatly limits the emission of nonspecific signals. The TR-FRET method combines standard FRET technology with the low background benefit of fluorescence (TRF) measurement based on extremely longlived emission of lanthanide complexes such as $\mathrm{Eu}^{3+} \subset$ Tris-bipyridine cryptate $(\mathrm{Eu}) \mathrm{K} .{ }^{33}$ First, rabbit tissue proteins were solubilized in four different buffers containing non-ionic and/or anionic detergents to access a wide panel of proteins. Every protein extract was then biotinylated according to three different molar ratios of proteins/biotin so as to yield a large degree of labeling. All of these reagents were pooled according to a 1:1 (v/v) ratio.

To minimize the background signal, the acceptor fluorophore streptavidin-XL665 needs to be used in nanomolar concentrations. ${ }^{31,32}$ Direct TR-FRET binding assay was monitored on solid phase to eliminate uncomplexed

Table 1. Selected Clones after Third Round of Panning and Number of Identical Sequences Found in Each Extracted Fraction

\begin{tabular}{lcccc}
\hline & \multicolumn{3}{c}{ Round 3 } & Final \\
\cline { 2 - 4 } Clone & F1 & F2 & F3 & frequency $(\%)^{*}$ \\
\hline H2.1 & 2 & 8 & 5 & 10 \\
C3.3 & 9 & 6 & 0 & 10 \\
K3.1 & 5 & 3 & 4 & 8 \\
F5.1 & 1 & 3 & 4 & 5.3 \\
I8.1 & 1 & 1 & 3 & 3.3 \\
K3.24 & 2 & 0 & 0 & 1.3 \\
\hline
\end{tabular}

*The sequence frequency represents the number of identical sequences identified from the pool of clones sequenced from round 3 . 


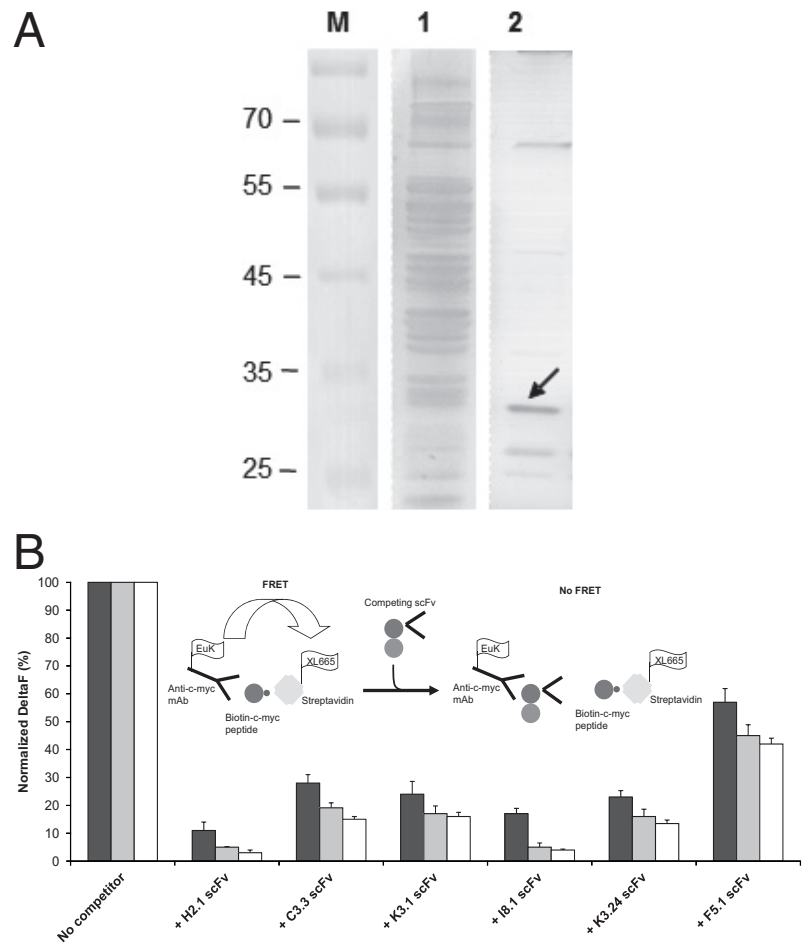

Figure 3. ScFv purification and inhibition of HTRF biotin-c-myc peptide sandwich signal. A: Example of 10\% SDS-PAGE obtained before (lane 1) and after (lane 2) immobilized metal affinity chromatography purification of induced $\mathrm{H} 2.1 \mathrm{scFv}$ soluble production. Arrow indicates the localization of $\mathrm{scFv}$ band, which was estimated at $30 \mu \mathrm{g} / \mathrm{mL}$ with the Bradford protein assay kit. Gels were stained with silver nitrate. Lane M: molecular size marker in kDa. B: HTRF sandwich assay principle is depicted at the top. The donor fluorophore europium cryptate (Eu)K conjugated to anti-c-myc mAb was able to recognize the c-myc tag of biotinylated peptide. The acceptor fluorophore XL665 conjugated to streptavidin-bound biotinylated amino acids of c-myc peptide. In the absence of competitors, a FRET sandwich signal generated by the biotin-c-myc peptide is recorded. Competition with scFvs for the c-myc tag abolished the FRET signal. The signals were measured in the presence of 0.4 $\mathrm{nmol} / \mathrm{L}$ of $\mathrm{mAb}-(\mathrm{Eu}) \mathrm{K}, 1.25 \mathrm{nmol} / \mathrm{L}$ of streptavidin-XL665, and 5 $\mathrm{nmol} / \mathrm{L}$ of biotin c-myc peptide. Five microliters of competitor were added to each well, corresponding to a final concentration between 5 and $170 \mathrm{nmol} / \mathrm{L}$ according to the $\mathrm{scFv}$ clone production and purification. The specific HTRF signal was measured as a percentage Delta F (percent Delta F) and normalized with regard to the maximum signal in the absence of competitor (taken as 100\%). The time course of competition was measured after 6 hours (black bars), 16 hours (gray bars), and 24 hours (white bars) of incubation at $4^{\circ} \mathrm{C}$. Histobar values represent the average of at least three independent experiments \pm SD performed from the same purified scFv production. biotinylated proteins to scFvs and thus avoid trapping of the fluorophore acceptors by the abundant and unspecific proteins. In these experimental conditions, streptavidin-XL665 could be used in the nanomolar range. The six purified scFvs were preadsorbed on wells and independently incubated with biotinylated protein extracts. After washing out unbound proteins and incubation with both fluorophore reporters, the time course of the assay revealed positive FRET signals for four scFvs, suggesting that they were able to recognize partners present within the protein soup (Figure 4). In addition, no binding signal was reported on a biotinylated control protein (data not shown). Importantly, in the binding assays, the TR-FRET signal intensity not only is proportional to the abundance of the cognate atheromatous antigen in the tissue extracts, but also depends on the quality and quantity of purified scFvs. For example, the F5.1 scFv weakly detected in the competitive HTRF sandwich assay (Figure 3) was certainly not concentrated ( $3 \mu \mathrm{g} / \mathrm{mL}$ in the fraction) or pure enough to generate a positive signal in the direct TR-FRET binding assay (Figure 4). Conversely, the specificity of the assay was shown through the highly purified and concentrated (100 $\mu \mathrm{g} / \mathrm{mL}) \mathrm{K} 3.24 \mathrm{scFv}$, which was strongly detected in the competitive HTRF assay but unable to generate a positive direct TR-FRET signal. These FRET signals were absent or very weak when the TR-FRET technique was performed in liquid phase, without coating and washing steps (data not shown).

To further confirm the specificity of the FRET signal recorded on the atheromatous proteins, a new set of experiments was performed in the presence of unlabeled rabbit protein extract used as competitor (Figure 5). As expected, a dose-dependent inhibition was observed with unbiotinylated atherosclerotic proteins and a six-fold excess of proteins was able to quench the Delta $\mathrm{F}$ binding values by approximately $75 \%, 80 \%$, and $60 \%$ for H2.1, 18.1, and K3.1 scFvs, respectively (Figure 5A). Moreover, the same experiments performed with a sixfold excess of proteins extracted from rabbits under standard diet also revealed an inhibition response but this was weaker, around $50 \%, 35 \%$, and $40 \%$ for $\mathrm{H} 2.1$, 18.1 , and K3.1 scFvs, respectively (Figure 5B). These results suggest that scFvs recognize binding partners that are more highly expressed in the lesional tissue of atheromatous rabbits fed a high-fat diet than in the tissue extracted from standard diet-fed rabbits developing early fatty streak lesions.

\section{Immunohistochemical Localization of scFvs on Rabbit and Human Aorta Sections}

ScFvs were tested for their ability to target ex vivo atherosclerotic sections obtained from thoracic aorta regions of 

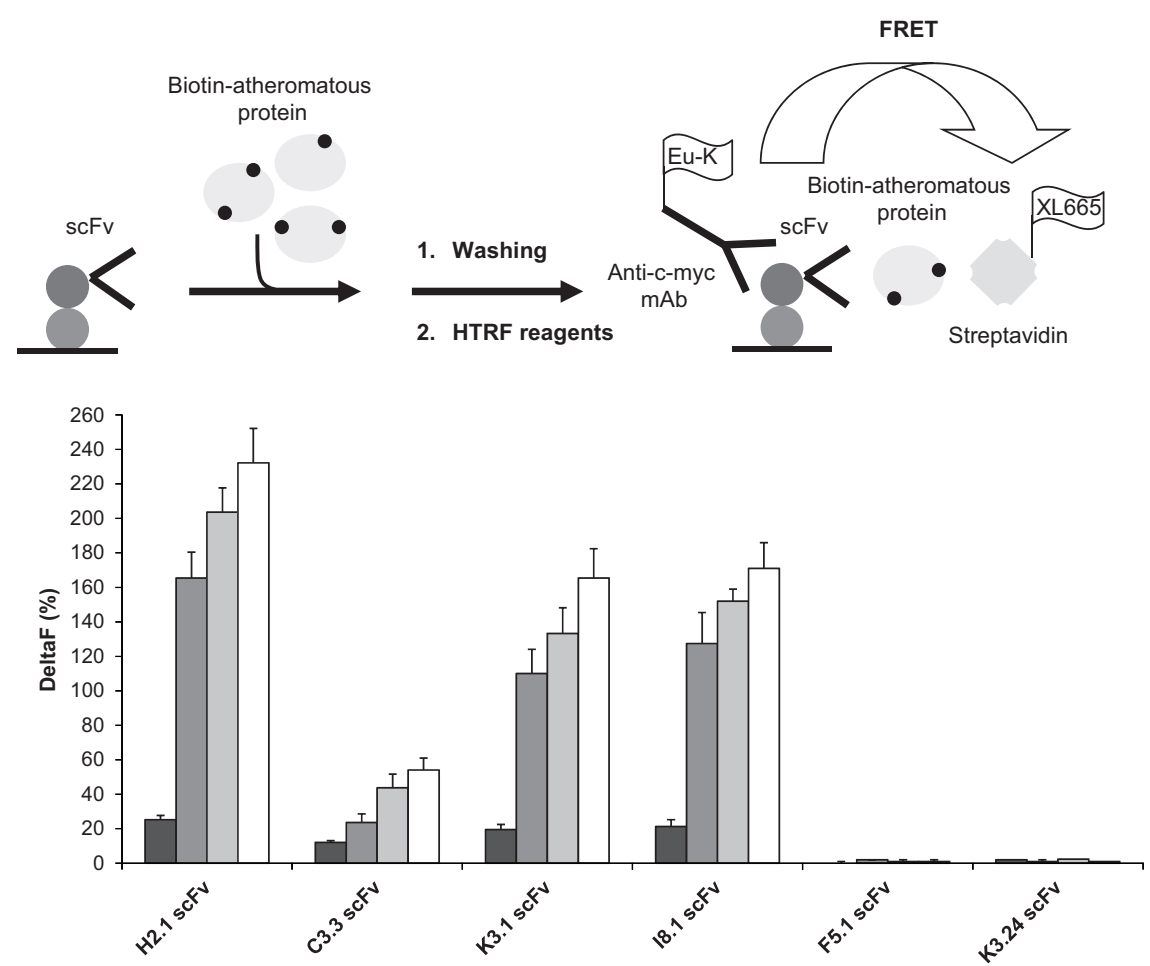

Figure 4. Direct TR-FRET binding assays between scFvs and atheromatous tissue extracts. The direct TRFRET principle is shown at the top. The donor fluorophore europium cryptate (Eu)K conjugated to anti-cmyc mAb was able to recognize the c-myc tag expressed by scFvs. The acceptor fluorophore XL665 conjugated to streptavidin-bound biotinylated protein extract. When scFvs bound to target proteins, a FRET signal was recorded. Excitation of the donor at $320 \mathrm{~nm}$ resulted in the fluorescence resonance transfer to the acceptor at $620 \mathrm{~nm}$, leading to the emission of the acceptor at $665 \mathrm{~nm}$. A specific TR-FRET signal was measured as a percentage Delta F. The time course of the detection of the complex formation was performed after 6 hours (black bars), 16 hours (dark gray bars), 24 hours (light gray bars), and 40 hours (white bars) of incubation at $4^{\circ} \mathrm{C}$. Ten microliters of $\mathrm{scFv}$ were coated on the plate at concentrations between 3 and $10 \mu \mathrm{g} / \mathrm{mL}$ according to the clone. The signals were measured in the presence of $4 \mathrm{nmol} / \mathrm{L}$ of $\mathrm{mAb}-(\mathrm{Eu}) \mathrm{K}, 4 \mathrm{nmol} / \mathrm{L}$ of streptavidin-XI 665 , and $30 \mu \mathrm{g} / \mathrm{mL}$ of biotinylated atheromatous protein extract or $50 \mu \mathrm{g} / \mathrm{mL}$ of biotinylated BSA (data not shown). Histobar values represent the average of at least three independent experiments \pm $\mathrm{SD}$ performed from the same purified $\mathrm{ScFv}$ production. hypercholesterolemic rabbits that had undergone an angioplasty. Endovascular local injuries are well known to potentiate atherogenesis and to mimic the vulnerable plaque formation in humans. ${ }^{34-36}$ Deparaffinized sections were incubated with selected scFvs and the binding then revealed by immunohistochemistry. Positive scFvs in the direct TR-FRET assay were able to recognize the atheromatous sections and showed very specific staining patterns (Figure 6). Although a diffuse extracellular labeling was found within the intima (Figure 6, A and C). H2.1 and K3.1 scFvs stained intensively both an area rich in macrophage- and smooth muscle cell-derived foam cells under endothelium and a deeper area rich in necrotic cells adjacent to the internal elastic lamina in the advanced lesion (Figure 6, A, B, C, and D). This staining was comparable to that observed with anti-macrophage RAM11 mAb (Figure 6I). Unlike staining patterns obtained with $\mathrm{H} 2.1$ and K3.1 scFvs, 18.1 scFv stained mostly endothelium and superficial subendothelial layers, whereas a weak labeling was also detected in the deeper intimal layers and in the adventitia (Figure 6, E and F). An intense specific staining within the lipid- and necrotic core-rich regions was revealed with C3.3 scFv (Figure 6G). Regarding the K3.24 scFv clone, there was no detectable binding through the section (Figure $6 \mathrm{H}$ ).

To further confirm the specificity of these clones, competitive binding assays on rabbit atherosclerotic sections were performed. Here, we illustrate the inhibition of biotinylated H2.1 scFv binding by a four-fold excess of its homologous unlabeled version (Figure 7). Compared to staining obtained in the absence of competitor (Figure 7 , $A$ and $B$ ), revelation with the streptavidin-HRP conjugate showed a net decrease in staining (Figure 7, C and D).
Standard NZW rabbit diets are not classically considered to promote the formation of atherosclerotic lesions. However, after a long life in the laboratory, rabbits are spontaneously susceptible to developing atheromatous lesions adjacent to apparently healthy areas. ${ }^{37}$ We observed such modifications in our standard diet-fed rabbits. In the atherosclerotic areas, staining with $\mathrm{H} 2.1 \mathrm{scFv}$ was predominantly associated with neointimal macrophage foam cells, although diffuse intimal labeling was also observed (Figure 8, A and B). Regarding 18.1 scFv, it mainly bound the endothelium cell surface of affected areas, even though diffuse light staining was also seen through the intima (Figure 8, D and E). Interestingly, the aortic regions without atherosclerotic intimal lesions did not reveal any intense staining with $\mathrm{H} 2.1$ and 18.1 scFvs. Only a weak labeling was detected on some endothelial cells (Figure $8, \mathrm{C}$ and $\mathrm{F}$ ).

H2.1 and 18.1 scFvs were also incubated onto human sections of carotid and coronary arteries obtained from endarterectomy and cardiac transplant recipients, respectively. Even though both arteries showed well-developed plaques, the coronary artery showed a more advanced lesional stage (Figure 9). Both scFvs exhibited binding patterns very close to those observed on rabbit atheroma sections. The localization of $\mathrm{H} 2.1 \mathrm{scFv}$ binding occurred predominantly within the foam cell-rich regions in the carotid (Figure 9A) and in the necrotic lipid-rich areas of the coronary artery (Figure 9B). I8.1 scFv staining was concentrated on the endothelium in the carotid (Figure 9C) and the coronary arteries (Figure 9D), even though a weak staining was also detectable in necrotic cores of the coronary artery compared to controls (Figure $9, \mathrm{E}$ and $\mathrm{F}$ ). 
A
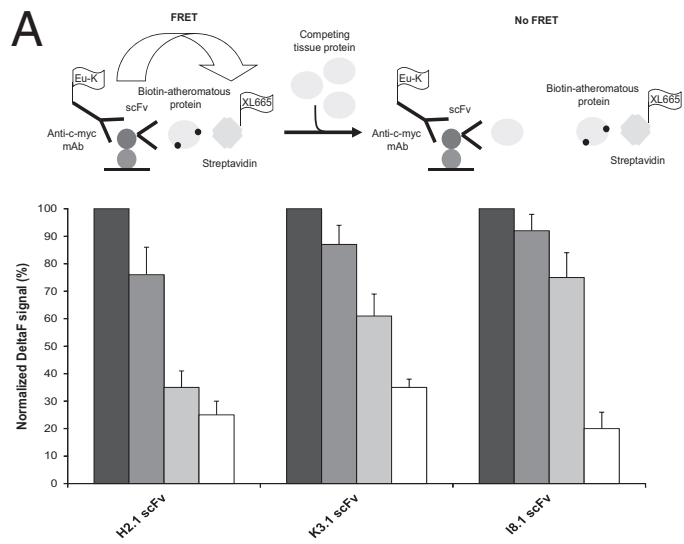

B

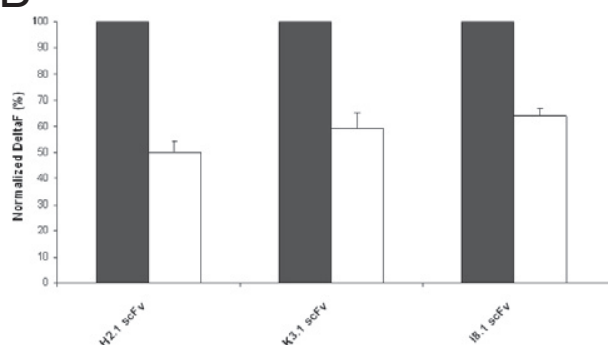

Figure 5. Inhibition of direct TR-FRET binding assays with unlabeled tissue extracts. Direct TR-FRET inhibition principle is shown at the top. The donor fluorophore europium cryptate (Eu)K conjugated to anti-c-myc mAb was able to recognize the c-myc tag expressed by scFvs. The acceptor fluorophore XL665 conjugated to streptavidin-bound biotinylated atherogenic protein extract. The FRET signal (Delta F \%) was then measured in the presence of 2.5-fold (dark gray bars), 5-fold (light gray bars), and 6-fold (white bars) excess of unlabeled protein extract from animals submitted to an atherogenic diet (A) and 6-fold (white bars) excess of unlabeled protein extract from animals fed a standard diet (B). The specific TR-FRET signal was measured as a percentage Delta $\mathrm{F}$ and normalized with regard to the signal obtained in the absence of competitor (taken as 100\%) (black bars). Ten microliters of scFv were coated onto the plate at concentrations between 3 and $10 \mu \mathrm{g} / \mathrm{mL}$ according to the clone. The signals were measured in the presence of 4 $\mathrm{nmol} / \mathrm{L}$ of mAb-(Eu)K, $4 \mathrm{nmol} / \mathrm{L}$ of streptavidin-XL $665,30 \mu \mathrm{g} / \mathrm{mL}$ of biotinylated atheromatous protein extract and monitored after 16 hours of incubation at $4{ }^{\circ} \mathrm{C}$. Histobar values represent the average of at least three independent experiments $\pm \mathrm{SD}$ performed from the same purified $\mathrm{scFv}$ production.

Taken altogether, these findings confirmed that the selected scFvs were able to home specifically to atherosclerotic endothelial and subendothelial areas in rabbit and in human. On the contrary, we observed no binding within the nonlesional arterial areas of rabbits fed a standard laboratory diet.

\section{CA-II Target Identification and ELISA Binding Assay of the K3.1 scFv}

To identify the molecule recognized by purified K3.1 scFv, immunoprecipitation experiments using nickel superparamagnetic beads were performed to retain 6 Histagged scFvs complexed to antigens contained in the rabbit atherosclerotic protein lysate. When separated by SDS-PAGE and silver stained, K3.1 scFv ( 32 kDa) bound a protein with an apparent molecular mass of $\sim 29$ $\mathrm{kDa}$ that did not appear in the controls performed in the absence of scFv or with irrelevant scFv (Figure 10A). After band excision and mass spectrometry analysis, three dodecapeptides fully matched with cytosolic CA-II, a 29-kDa protein that seemed to be the putative binding antigen recognized by the $\mathrm{K} 3.1 \mathrm{scFv}$. Interestingly, this rabbit protein showed more than $85 \%$ homology with the corresponding human protein.
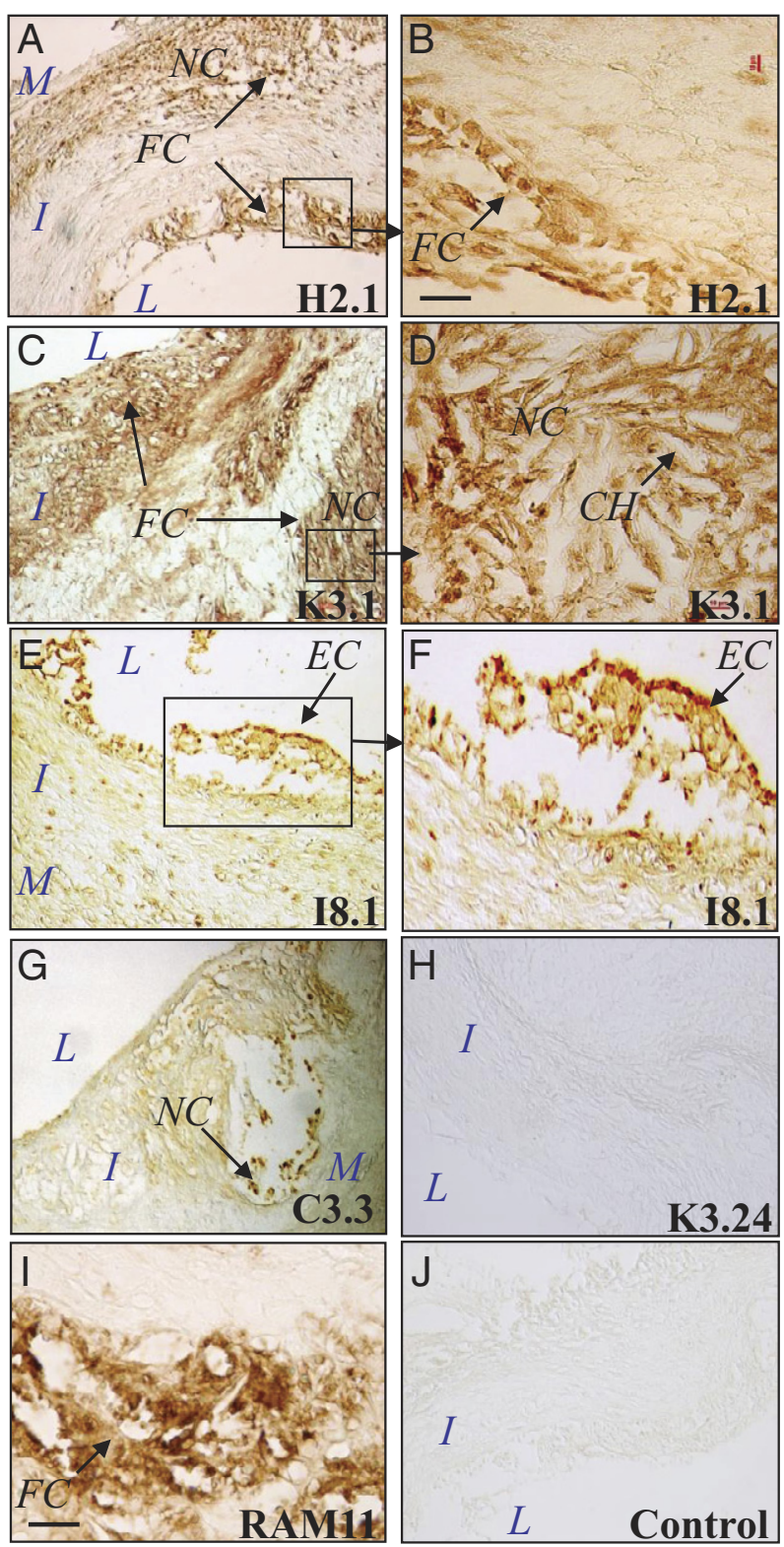

$J$

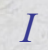

Figure 6. Immunodetection of scFvs homing to advanced atherosclerotic lesion from balloon-catheterized, cholesterol-fed NZW rabbit sections. Selected scFvs and irrelevant control scFv (random CDRH3 and CDRL3) were incubated on rabbit tissue sections at final concentrations of $2 \mu \mathrm{g} / \mathrm{mL}, 5 \mu \mathrm{g} / \mathrm{mL}, 10 \mu \mathrm{g} / \mathrm{mL}, 12.5 \mu \mathrm{g} / \mathrm{mL}$, and $16.5 \mu \mathrm{g} / \mathrm{mL}$ for C3.3, H2.1, K3.1, I8.1, and K3.24 scFvs, respectively. After adding secondary antibodies as described in Materials and Methods, sections were revealed with the Vectastain $\mathrm{ABC}$ kit reagent. The presence of the antigen recognized by scFvs was indicated by a yellow-brown stain. Incubation with $\mathrm{H} 2.1 \mathrm{scFv}(\mathbf{A}$ and $\mathbf{B})$ $\mathrm{K} 3.1 \mathrm{scFv}(\mathbf{C}$ and $\mathbf{D})$; $18.1 \mathrm{scFv}(\mathbf{E}$ and $\mathbf{F}) ; \mathrm{C} 3.3 \mathrm{scFv}(\mathbf{G}) ; \mathrm{K} 3.24 \mathrm{scFv}(\mathbf{H})$ revealed the specific localization of each binding. (B), (D), and (F) showed higher magnifications of areas targeted by H2.1, K3.1, and I8.1 scFvs, respectively. Foam cell-rich advanced atherosclerotic lesions were stained with RAM11 mAb (positive control) (I), whereas incubation with $15 \mu \mathrm{g} / \mathrm{mL}$ of control scFv produced no staining (J). H2.1 and K3.1 scFvs predominantly targeted cells located within the subendothelial layer and in the necrotic core region, resembling the stain obtained from the RAM11 antibody. We noted the presence of cholesterol crystals in the necrotic core region. I8.1 scFv revealed the endothelial cell surface, whereas deeper layers were relatively unstained. C3.3 scFv predominantly stained the necrotic core region. No staining was detected with K3.24 scFv. CH, cholesterol; EC, endothelial cell; FC, foam cell; I, intima; L, artery lumen; M, media; NC, necrotic core. Scale bars represent $100 \mu \mathrm{m}$ and $10 \mu \mathrm{m}$ in enlarged views. 

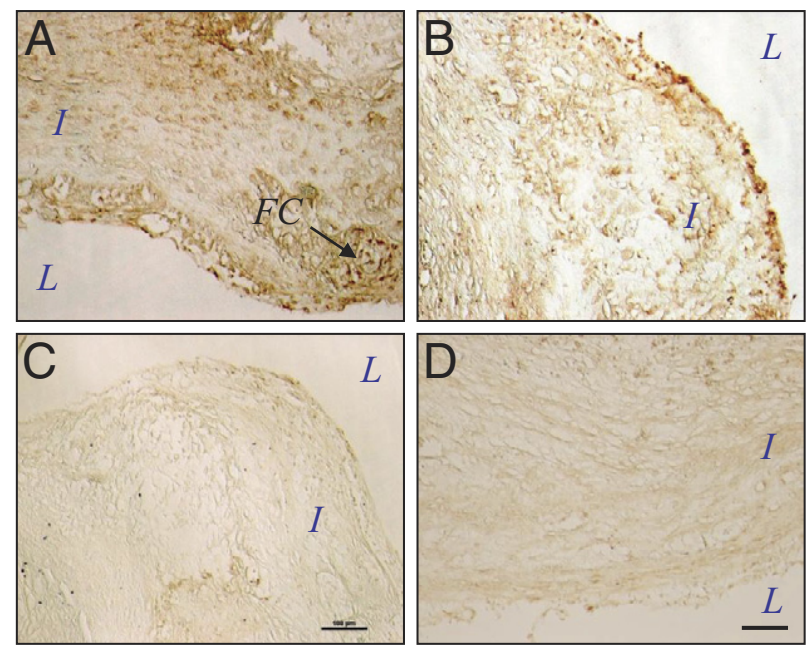

Figure 7. Inhibition of $\mathrm{H} 2.1 \mathrm{scFv}$ binding on rabbit atherosclerotic sections. Staining of biotinylated $\mathrm{H} 2.1 \mathrm{scFv}(5 \mu \mathrm{g} / \mathrm{mL})$ was performed in the absence (A and $\mathbf{B}$ ) or presence of a four-fold excess of unlabeled H2.1 scFv (C and D). Biotinylated H2.1 scFv was revealed with streptavidin-HRP conjugate and Vectastain ABC substrate kit. In the presence of unlabeled $\mathrm{H} 2.1$, a significant decrease in staining in the subendothelial and necrotic regions was observed. FC, foam cell; I, intima; L, artery lumen. Scale bars $=100 \mu \mathrm{m}$.

To further confirm the binding specificity of K3.1 scFv, an ELISA was performed on a commercial human recombinant CA-II antigen. Binding signals obtained on CA-II confirmed the immunoreactivity of K3.1 scFv with this target (Figure 10B).

\section{Discussion}

In Vivo Phage Display Technology Is a Promising Panning Procedure to Investigate the Molecular Repertoire of Diseased Endothelial and Subendothelial Tissues in Living Animals

We report here the use of a semisynthetic human scFv library ${ }^{28}$ to interrogate the molecular repertoire expressed within atherosclerotic lesions under in vivo conditions. In vivo selection, through the wide panel of pathological biomarkers targeted on vasculature, indeed offers a wide choice of new target/ligand pairs. ${ }^{24,38,39}$ To optimize this selection, we decided to perform three successive rounds of panning to amplify the best hits (Figure 1). Moreover, circulating times were chosen so as to fit both with the serum half-life of phages ${ }^{30}$ and the conditions for ligand-induced receptor internalization..$^{40}$

The in vivo phage biopanning approach is usually limited to the accessible targets covering the vasculature surface, since the extravasation of phages toward subjacent tissues is thought to be very limited. ${ }^{41}$ Nevertheless, Molenaar et al ${ }^{40}$ showed that a small proportion of phages could be taken up by subendothelial parenchymal cells. In our study, we eluted only two-fold fewer phage scFvs within the subendothelial intimal tissue than on the vascular surface. This was the case from the first round of selection (data not shown). A leaky dysfunctional endothelium and a dense microvascular network of vasa vasorum that extends deeply from the adventitia and outer media toward the intima ${ }^{42}$ are hypothesized as being the ways used by phage scFvs to reach the deeper layers of the intima. Consequently, our experimental conditions made it possible to select scFvs stripped from the endothelial cell surface (F1 fraction), buried in the subendothelial cellular and extracellular tissue (F2 fraction), and endocytosed by the cells constituting the intimal wall (F3 fraction) (Figures 1 and 2).

Random sequencing of clones from each fraction identified identical scFv sequences in several fractions, suggesting the presence of targets expressed on cells infiltrating the vascular wall (Table 1).

These observations show that the development of specific phage scFvs, directly targeting the molecular repertoire associated with atherogenic lesions, can be achieved through in vivo phage display technology.

\section{Functional Screening Approaches Identify New Lesion-Specific Homing Ligands for the Diagnosis and Treatment of Atherosclerosis}

In vivo selections performed with random peptide libraries make it possible to identify relevant peptides from sequence homology comparisons with known receptor ligands. ${ }^{14,15,43}$ The screening of potential scFv binders is markedly more complex and requires the development of robust screening approaches to identify scFvs targeting one particular biomarker among thousands of proteins
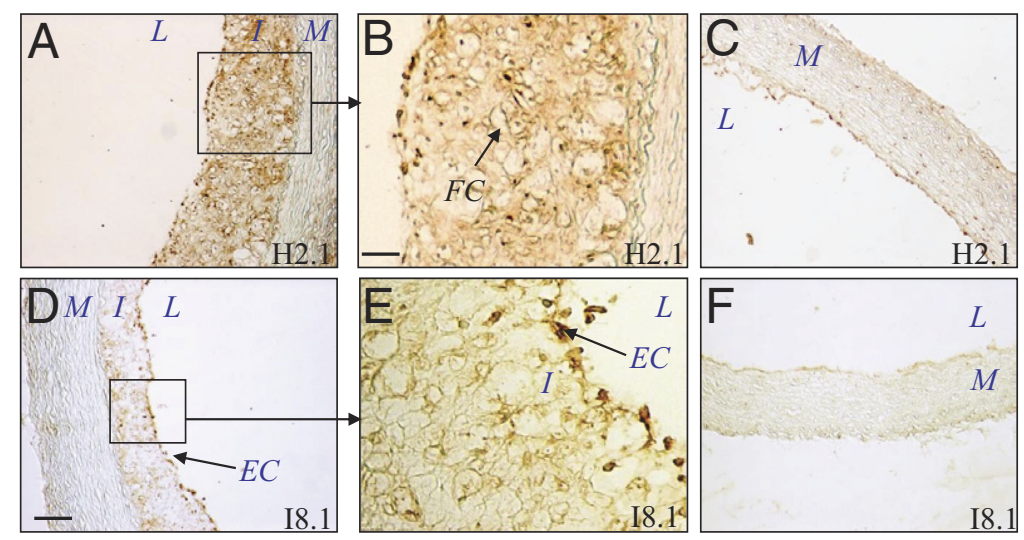

Figure 8. Immunodetection of $\mathrm{H} 2.1$ and $\mathrm{I} 8.1 \mathrm{scFvs}$ to healthy aorta and early atherosclerotic lesions in rabbit fed a standard diet. H2.1 and $\mathrm{I} 8.1 \mathrm{scFvs}(5 \mu \mathrm{g} / \mathrm{mL}$ and $12.5 \mu \mathrm{g} / \mathrm{mL}$, respectively) were incubated on sections of normal diet-fed rabbits exhibiting both pathological $(\mathbf{A}, \mathbf{B}, \mathbf{D}$, and $\mathbf{E})$ and nonlesional regions along the artery $(\mathbf{C}$, and $\mathbf{F})$. H2.1 scFv staining was observed within the macrophage-rich early atherosclerotic lesions (A). A greater magnification of the foamcell area targeted by H2.1 scFv gave details of this staining (B). I8.1 scFv staining was essentially localized on the endothelium surface of the early atheroma ( $\mathbf{D}$, higher magnification in E). H2.1 and I8.1 scFvs showed only weak and scattered staining on some endothelial cells along the normal intimal areas (C and $\mathbf{F})$. A, adventitia; EC, endothelial cell; FC, foam cells; I, intima; L, artery lumen; M, media. Scale bars represent $100 \mu \mathrm{m}$ and $10 \mu \mathrm{m}$ in enlarged views. 


\section{Human carotid}
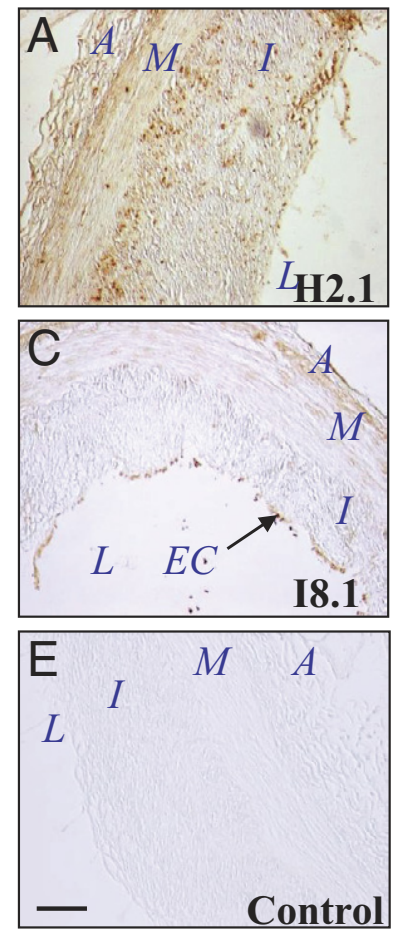

\section{Human coronary}
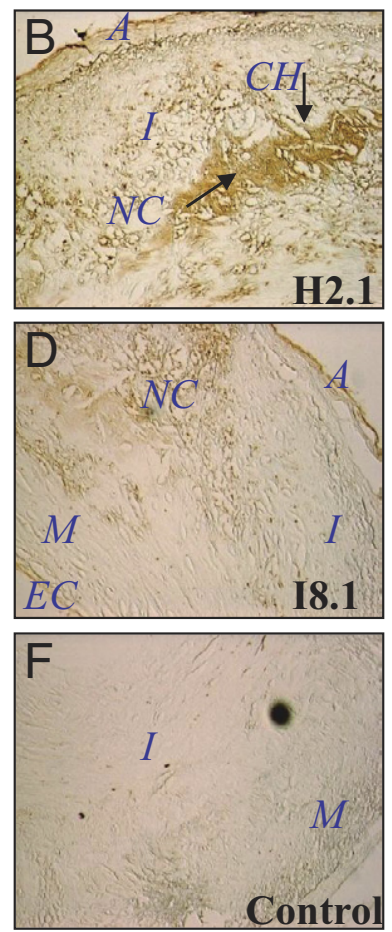

Figure 9. Immunodetection of $\mathrm{H} 2.1$ and $\mathrm{I} 8.1 \mathrm{scFvs}$ to atherosclerotic lesions of human carotid and coronary arteries. Selected H2.1 and I8.1 scFvs (5 $\mu \mathrm{g} / \mathrm{mL}$ and $12.5 \mu \mathrm{g} / \mathrm{mL}$, respectively) and irrelevant control scFv $(15 \mu \mathrm{g} / \mathrm{mL})$ were incubated on human atherosclerotic sections. Staining with $\mathrm{H} 2.1 \mathrm{scFv}$ occurred mostly within foam cell-rich regions in carotid early lesions (A) and within necrotic and lipid-rich areas of advanced lesions of the coronary artery (B). We noted the presence of cholesterol crystals in the advanced lesions. I8.1 $\mathrm{scFv}$ showed a staining pattern targeting the endothelial layer both in advanced lesions in carotid (C) and coronary arteries (D), although diffuse labeling was also observed in other regions. Irrelevant scFv (random CDR3) yielded no staining ( $\mathbf{E}$ and $\mathbf{F}$ ). A, adventitia; $\mathrm{CH}$, cholesterol; EC, endothelial cell; $\mathrm{I}$, intima; L, artery lumen; M, media; NC, necrotic core. Scale bars $=100 \mu \mathrm{m}$.

isolated from the atherosclerotic lesions. To circumvent these difficulties, we implemented a highly sensitive fluorescent screening assay based on TR-FRET ${ }^{33}$ to identify scFvs able to recognize partners present within an atheromatous protein lysate. Rabbit homogenous protein extract was used in this in vitro assay. We reasoned that selecting human antibodies in ApoE mice and screening the candidates on rabbit atheromatous lysates would give us the best possible chance of selecting human antibodies targeting conservative epitopes within species. A TR-FRET signal was detected for four scFvs among six selected on the basis of overrepresented amino acid sequences (Figure 4). The specificity of these signals has been demonstrated through the inhibition of about $70 \%$ of fluorescence emission for three scFvs in the presence of a six-fold excess of unlabeled atheromatous proteins (Figure 5A). The same experiment performed with an excess of unlabeled aortic proteins from rabbits fed a standard diet showed a weaker signal inhibition (Figure 5B). Histological observations of aorta sections from rabbit fed a standard diet revealed the existence of foam cell-rich intimal thickenings typical of early atherogenesis in some segments along the vessel. These affected zones and some endothelial cells of nonlesional

areas were recognized by the scFvs (Figure 8). These observations suggested that the signal inhibition observed in TR-FRET with proteins extracted from rabbits fed a standard diet may be due to the presence of atherogenic components within pre-atherogenic and early fatty streak lesional zones.

To further validate the in vitro TR-FRET binding, we performed ex vivo immunohistochemistry analyses on atherosclerotic tissues from hypercholesterolemic rabbit and from human lesional arteries. These observations will also provide information about the interspecies homology of recognized epitopes. The four positive TR-FRET scFvs were able to stain both rabbit and human atherosclerotic tissue sections (Figures 6, 7, and 9).

In rabbit and human plaques, staining with $\mathrm{H} 2.1$ and K3.1 scFvs was predominantly associated with areas rich in foam cells and lipid-rich necrotic cores. $18.1 \mathrm{scFv}$ mainly stained the endothelium cell surface and superficial suben-
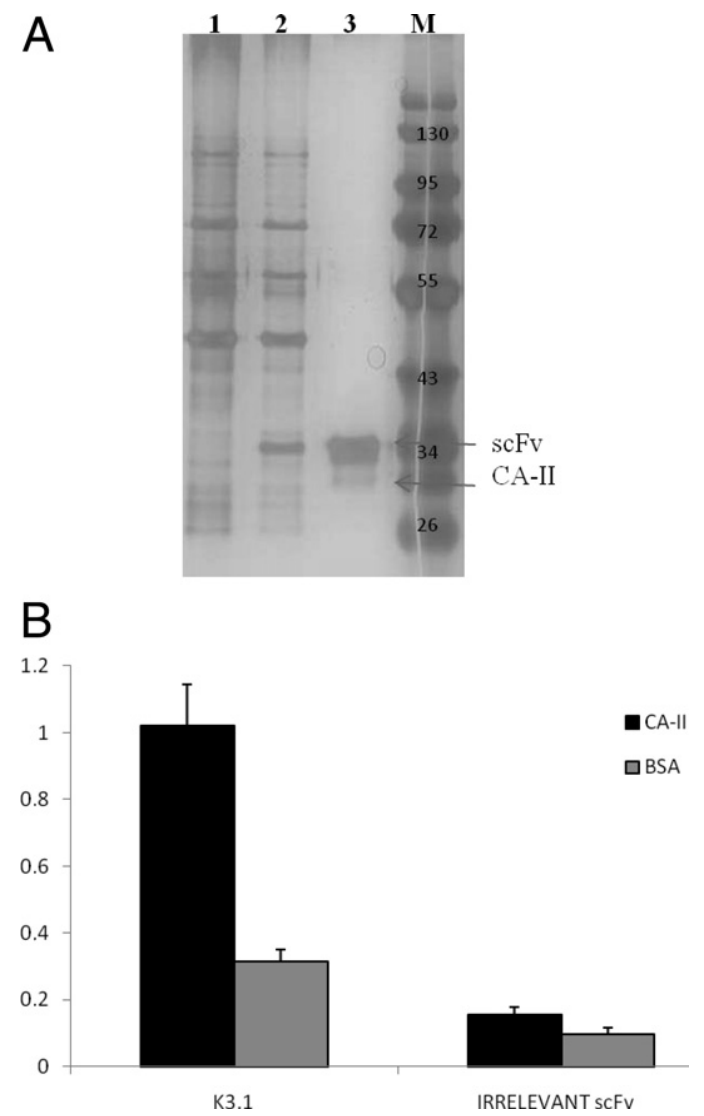

Figure 10. Target identification of $K 3.1 \mathrm{scFv}$ and ELISA binding assay. A: Rabbit atheromatous protein lysate $(1 \mathrm{mg})$ immunoprecipitated with $10 \mu \mathrm{g}$ of $\mathrm{K} 3.1 \mathrm{scFv}$ or an irrelevant scFv (random CDRH3 and CDRL3) was separated on 10\% SDS-PAGE under reducing conditions and revealed by silver nitrate staining. One microliter of proteins precipitated with K3.1 scFv (lane 3) was compared with $1 \mu \mathrm{L}$ of the irrelevant scFv immunoprecipitates (lane 2). A control was performed without $\mathrm{scFv}$ (lane 1 ). The protein band at $\sim 29 \mathrm{kDa}$ corresponding to the immunoprecipitated target was excised after SDS-PAGE, digested in trypsin, and submitted to liquid chromatography-tandem mass spectrometry proteomic analysis. Lane M: molecular size marker in kDa. B: ELISA of K3.1 scFv on bovine serum albumin $(50 \mu \mathrm{g} / \mathrm{mL})$ or human cytosolic carbonic anhydrase II $(10 \mu \mathrm{g} / \mathrm{mL})$ coated overnight onto a 96-well ELISA plate in $\mathrm{NaHCO}_{3}$ buffer ( $\mathrm{pH}$ 9.6). K3.1 scFv was detected with a mix of HRP conjugated anti-c-myc (diluted 1:1000) and anti 6His (diluted 1:500) mAbs followed by color development with TMB liquid substrate system for ELISA (Sigma-Aldrich). Absorbances were measured at $450 \mathrm{~nm}$ with a Tecan Infinite 500 microplate reader. 
dothelial layers, whereas C3.3 scFv staining was more localized around the lipid-rich necrotic cores. The very low level of staining observed in the nonlesional areas of standard diet-fed rabbits with $\mathrm{H} 2.1$ and 18.1 scFvs strongly suggested that binding partners were certainly absent or weakly expressed in these unaffected zones (Figure 8).

These observations show that scFvs are able to target distinct markers expressed in specific regions of intimal lesions, a binding that is highly dependent on the stage of advancement of plaque formation. The same patterns of staining observed in diseased rabbit and human affected sections (Figures 6, 7, and 9) suggested a strict conservation of targeted epitopes among species. We underline the value of selecting human antibodies able to target relevant biomarkers highly expressed both in animal models of atherosclerosis and in humans, to achieve translational developments from preclinical to clinical phases. Human antibodies targeting human biomarkers are mandatory for use in humans to meet safety requirements. Adverse complications due to host-immune recognition are widely observed following repeated injections of rodent antibodies in humans. Nevertheless, it is vital to select human antibodies that could also be tested in animal models of the disease in preclinical studies. The identification of cross-reactive targets is regarded as necessary for translational studies. In turn, there are limitations regarding the identification of antigens that are not sufficiently homologous across species.

\section{CA-ll as an in Vivo Imaging Biomarker and Potential Therapeutic Target in Atherosclerosis Highlighted by in Vivo Phage Display Technology}

These experiments represent an entirely new approach, not only to identify lesion-specific homing ligands, but also to shed light on cognate up-regulated lesion-associated targets. Our data show how the target within rabbit lesional lysate can be successfully identified by combining in vivo phage display biotechnology with immunoprecipitation of scFv/target pairs. The human antibody fragment K3.1 was found to target a $29-\mathrm{kDa}$ protein corresponding to cytosolic carbonic anhydrase CA-II, an enzyme that determines the rate of conversion of carbon dioxide to bicarbonate and carbonic acid (Figure 10A). ELISA assay on purified protein confirmed the binding specificity and suggested that the human homologue was also recognized (Figure 10B). The presence of CA-II has been recently reported in human atherosclerotic plaques. ${ }^{44} \mathrm{CA}-\|$ expression is known to be an important regulator of calcium levels and ectopic calcification. ${ }^{45}$ Indeed, CA-II is abundantly found in the cytoplasm of a wide number of cells, especially osteoclasts, ${ }^{46}$ and is strongly overexpressed in a subset of monocyte-derived macrophages and osteoclast-like cells recruited within ectopic vascular mineralization. ${ }^{26}$ The osteoclast-like cells are the cellular mediators of arterial mineral resorption within the atherosclerotic plaques which frequently develop vascular calcium deposits. ${ }^{47,48}$ Macrophages, which are widely present during all stages of atherosclerosis, are an abundant source of preosteoclasts. ${ }^{47,49}$
K3.1 scFv strongly stained areas rich in macrophagederived foam cells under the endothelium and a deeper zone rich in necrotic cells (Figure 6, C and D). Macrophages in advanced lesions accumulate large amounts of cholesterol that trigger their cell death. ${ }^{50}$ Cells dying by apoptosis and necrosis may trigger the release of their cellular contents. Thus, dying macrophages displaying an osteoclast-like phenotype might be an abundant source of extracellular CA-II.

Identification of K3.1 scFv targeting CA-II antigen expressed within the macrophage-rich necrotic core indicated that circulating phage scFvs were able to reach the subjacent lesional tissue layers. By identifying CA-II as an accessible target overexpressed in atherosclerotic plaque, our approach underlines the value of CA-II as an accurate biomarker for in vivo imaging of atherosclerosis. Although calcification is a well-known feature of atherosclerotic plaques, its potential role in onset of plaque instability is still a matter of debate. Which kind of calcification are we talking about, small and multiple calcium deposits, or severe calcified regions? Instability has been recently related to these dispersed microcalcifications, which could increase local stress in the fibrous cap and lead to plaque rupture. ${ }^{51}$ By contrast, severe calcified lesions are much stiffer than cellular lesions and are thus unlikely to be associated with sites of plaque rupture. ${ }^{52}$ Up-regulation of CA-II may be considered a defensive mechanism in the plaques since CA-II promotes mineral resorption. So, an important clinical issue is whether inhibition or augmentation of CA-II in unstable plaques would promote stabilization or destabilization of the plaque. Future mechanistic studies are a needed to understand how modulation of CA-II function could affect the stability of the vulnerable plaque.

It is now well accepted that sudden cardiovascular events often result from plaque rupture at sites with no or only modest arterial stenosis at angiography, underlining the fact that the plaque composition rather than the degree of narrowing is a critical determinant of vulnerability and thrombogenicity. ${ }^{53}$ Furthermore, vascular calcification is regarded as a key factor of plaque instability besides local vascular injury, inflammation, and oxidative stress. ${ }^{48}$ Gamble $^{54}$ proposed that the determinant regulator of the metabolic processes leading to the prevention of atherosclerosis is carbonic anhydrase.

All things considered, in vivo phage display offers the advantage of discovering new biomarkers up-regulated in the pathology and targeted in situ by human scFv fragments. The human scFvs reported here represent stepping stones for fundamental mechanistic studies and the development of novel agents for targeted therapies, as well as for the noninvasive molecular imaging of atherosclerosis. In a recent paper, ${ }^{55}$ we reported an in vivo magnetic resonance imaging assay for visualizing P-selectin target with a specific magnetic resonance contrast agent, using a murine anti-P-selectin antibody. This proof-of-concept will lay the basis for further development of magnetic resonance contrast agents functionalized with human antibodies that could be directly translated into human clinical use. 


\section{Acknowledgments}

We thank Dr. Pierre Martineau for providing the scFv library and for fruitful discussions. We also thank Drs. Laurent Barandon, Franscesco Madonna, and MarcAlain Billes for their helpful contribution in the collection of human tissue specimens. Special thanks also go to Dr. Martine Cérutti for helpful comments during the course of this project. This study was performed thanks to the Plateforme Technologique d'Innovation Biomédicale.

\section{References}

1. Miller NE: Associations of high-density lipoprotein subclasses and apolipoproteins with ischemic heart disease and coronary atherosclerosis. Am Heart J 1987, 113:589-597

2. Wood D, De Backer G, Faergeman O, Graham I, Mancia G, Pyorala K: Prevention of coronary heart disease in clinical practice: recommendations of the Second Joint Task Force of European and other Societies on Coronary Prevention. Atherosclerosis 1998, 140:199-270

3. Williams KJ, Tabas I: Atherosclerosis-an inflammatory disease. N Engl J Med 1999, 340:1928; author reply 1929

4. Genest JJ, McNamara JR, Salem DN, Schaefer EJ: Prevalence of risk factors in men with premature coronary artery disease. Am J Cardiol 1991, 67:1185-1189

5. Rader DJ, Daugherty A: Translating molecular discoveries into new therapies for atherosclerosis. Nature 2008, 451:904-913

6. Sanz J, Fayad ZA: Imaging of atherosclerotic cardiovascular disease. Nature 2008, 451:953-957

7. Blanco-Colio LM, Martin-Ventura JL, Vivanco F, Michel JB, Meilhac O, Egido J: Biology of atherosclerotic plaques: what we are learning from proteomic analysis. Cardiovasc Res 2006, 72:18-29

8. Wickline SA, Neubauer AM, Winter PM, Caruthers SD, Lanza GM: Molecular imaging and therapy of atherosclerosis with targeted nanoparticles. J Magn Reson Imaging 2007, 25:667-680

9. Shaw SY: Molecular imaging in cardiovascular disease: targets and opportunities. Nat Rev Cardiol 2009, 6:569-579

10. Antoniades C, Psarros C, Tousoulis D, Bakogiannis C, Shirodaria C, Stefanadis C: Nanoparticles: a promising therapeutic approach in atherosclerosis. Curr Drug Deliv 2010, 7:303-311

11. Koenig W, Khuseyinova N: Biomarkers of atherosclerotic plaque instability and rupture. Arterioscler Thromb Vasc Biol 2007, 27:15-26

12. Briley-Saebo KC, Mulder WJ, Mani V, Hyafil F, Amirbekian V, Aguinaldo JG, Fisher EA, Fayad ZA: Magnetic resonance imaging of vulnerable atherosclerotic plaques: current imaging strategies and molecular imaging probes. J Magn Reson Imaging 2007, 26 : $460-479$

13. Kelly KA, Nahrendorf M, Yu AM, Reynolds F, Weissleder R: In vivo phage display selection yields atherosclerotic plaque targeted peptides for imaging. Mol Imaging Biol 2006, 8:201-207

14. Liu C, Bhattacharjee G, Boisvert W, Dilley R, Edgington T: In vivo interrogation of the molecular display of atherosclerotic lesion surfaces. Am J Pathol 2003, 163:1859-1871

15. Houston P, Goodman J, Lewis A, Campbell CJ, Braddock M: Homing markers for atherosclerosis: applications for drug delivery, gene delivery and vascular imaging. FEBS Lett 2001, 492:73-77

16. Pasqualini $R$, Ruoslahti E: Organ targeting in vivo using phage display peptide libraries. Nature 1996, 380:364-366

17. Tsourkas A, Shinde-Patil VR, Kelly KA, Patel P, Wolley A, Allport JR, Weissleder R: In vivo imaging of activated endothelium using an antiVCAM-1 magnetooptical probe. Bioconjug Chem 2005, 16:576-581

18. Amirbekian V, Lipinski MJ, Briley-Saebo KC, Amirbekian S, Aguinaldo JG, Weinreb DB, Vucic E, Frias JC, Hyafil F, Mani V, Fisher EA, Fayad ZA: Detecting and assessing macrophages in vivo to evaluate atherosclerosis noninvasively using molecular MRI. Proc Natl Acad Sc U S A 2007, 104:961-966

19. McAteer MA, Schneider JE, Ali ZA, Warrick N, Bursill CA, von zur Muhlen C, Greaves DR, Neubauer S, Channon KM, Choudhury RP: Magnetic resonance imaging of endothelial adhesion molecules in mouse atherosclerosis using dual-targeted microparticles of iron oxide. Arterioscler Thromb Vasc Biol 2008, 28:77-83
20. Lipinski MJ, Frias JC, Amirbekian V, Briley-Saebo KC, Mani V, Samber D, Abbate A, Aguinaldo JG, Massey D, Fuster V, Vetrovec GW, Fayad ZA: Macrophage-specific lipid-based nanoparticles improve cardiac magnetic resonance detection and characterization of human atherosclerosis. JACC Cardiovasc Imaging 2009, 2:637-647

21. Robert R, Jacobin-Valat MJ, Daret D, Miraux S, Nurden AT, Franconi JM, Clofent-Sanchez G: Identification of human scFvs targeting atherosclerotic lesions: selection by single round in vivo phage display. J Biol Chem 2006, 281:40135-40143

22. Johns M, George AJ, Ritter MA: In vivo selection of sFv from phage display libraries. J Immunol Methods 2000, 239:137-151

23. Ueberberg S, Meier JJ, Waengler C, Schechinger W, Dietrich JW, Tannapfel A, Schmitz I, Schirrmacher R, Koller M, Klein HH, Schneider S: Generation of novel single-chain antibodies by phage-display technology to direct imaging agents highly selective to pancreatic beta- or alpha-cells in vivo. Diabetes 2009, 58:2324-2334

24. Krag DN, Shukla GS, Shen GP, Pero S, Ashikaga T, Fuller S, Weaver DL, Burdette-Radoux S, Thomas C: Selection of tumor-binding ligands in cancer patients with phage display libraries. Cancer Res 2006, 66:7724-7733

25. O'Neill TP: Apolipoprotein E-deficient mouse model of human atherosclerosis. Toxicol Pathol 1997, 25:20-21

26. Steitz SA, Speer MY, McKee MD, Liaw L, Almeida M, Yang H, Giachelli CM: Osteopontin inhibits mineral deposition and promotes regression of ectopic calcification. Am J Pathol 2002, 161:2035-2046

27. Lee SM, Lee EJ, Hong HY, Kwon MK, Kwon TH, Choi JY, Park RW, Kwon TG, Yoo ES, Yoon GS, Kim IS, Ruoslahti E, Lee BH: Targeting bladder tumor cells in vivo and in the urine with a peptide identified by phage display. Mol Cancer Res 2007, 5:11-19

28. Philibert P, Stoessel A, Wang W, Sibler AP, Bec N, Larroque C, Saven JG, Courtete J, Weiss E, Martineau P: A focused antibody library for selecting scFvs expressed at high levels in the cytoplasm. BMC Biotechnol 2007, 7:81

29. Curtiss LK, Boisvert WA: Apolipoprotein E and atherosclerosis. Curr Opin Lipidol 2000, 11:243-251

30. Zou J, Dickerson MT, Owen NK, Landon LA, Deutscher SL: Biodistribution of filamentous phage peptide libraries in mice. Mol Biol Rep 2004, 31:121-129

31. Maurel D, Kniazeff J, Mathis G, Trinquet E, Pin JP, Ansanay H: Cell surface detection of membrane protein interaction with homogeneous time-resolved fluorescence resonance energy transfer technology. Anal Biochem 2004, 329:253-262

32. Albizu L, Teppaz G, Seyer R, Bazin H, Ansanay H, Manning M, Mouillac B, Durroux T: Toward efficient drug screening by homogeneous assays based on the development of new fluorescent vasopressin and oxytocin receptor ligands. J Med Chem 2007, 50:49764985

33. Bazin $H$, Trinquet E, Mathis G: Time resolved amplification of cryptate emission: a versatile technology to trace biomolecular interactions. J Biotechnol 2002, 82:233-250

34. Rekhter MD, Hicks GW, Brammer DW, Work CW, Kim JS, Gordon D, Keiser JA, Ryan MJ: Animal model that mimics atherosclerotic plaque rupture. Circ Res 1998, 83:705-713

35. Weidinger FF, McLenachan JM, Cybulsky MI, Fallon JT, Hollenberg NK, Cooke JP, Ganz P: Hypercholesterolemia enhances macrophage recruitment and dysfunction of regenerated endothelium after balloon injury of the rabbit iliac artery. Circulation 1991, 84:755-767

36. Stary HC: Natural history and histological classification of atherosclerotic lesions: an update. Arterioscler Thromb Vasc Biol 2000, 20: 1177-1178

37. Bragdon $\mathrm{JH}$ : Spontaneous atherosclerosis in the rabbit. Circulation 1952, 5:641-646

38. Arap W, Kolonin MG, Trepel M, Lahdenranta J, Cardo-Vila M, Giordano RJ, Mintz PJ, Ardelt PU, Yao VJ, Vidal Cl, Chen L, Flamm A, Valtanen $\mathrm{H}$, Weavind LM, Hicks ME, Pollock RE, Botz GH, Bucana CD, Koivunen E, Cahill D, Troncoso P, Baggerly KA, Pentz RD, Do KA, Logothetis CJ, Pasqualini R: Steps toward mapping the human vasculature by phage display. Nat Med 2002, 8:121-127

39. Rajotte D, Arap W, Hagedorn M, Koivunen E, Pasqualini R, Ruoslahti $\mathrm{E}$ : Molecular heterogeneity of the vascular endothelium revealed by in vivo phage display. J Clin Invest 1998, 102:430-437

40. Molenaar TJ, Michon I, de Haas SA, van Berkel TJ, Kuiper J, Biessen EA: Uptake and processing of modified bacteriophage M13 in mice: implications for phage display. Virology 2002, 293:182-191 
41. Pasqualini R, Arap W, McDonald DM: Probing the structural and molecular diversity of tumor vasculature. Trends Mol Med 2002 8:563-571

42. Doyle B, Caplice N: Plaque neovascularization and antiangiogenic therapy for atherosclerosis. J Am Coll Cardiol 2007, 49:2073-2080

43. Yao VJ, Ozawa MG, Trepel M, Arap W, McDonald DM, Pasqualini R: Targeting pancreatic islets with phage display assisted by laser pressure catapult microdissection. Am J Pathol 2005, 166:625-636

44. Oksala N, Levula M, Pelto-Huikko M, Kytomaki L, Soini JT, Salenius J, Kahonen M, Karhunen PJ, Laaksonen R, Parkkila S, Lehtimaki T: Carbonic anhydrases II and XII are up-regulated in osteoclast-like cells in advanced human atherosclerotic plaques-Tampere Vascular Study. Ann Med 2010, 42:360-370

45. Rajachar RM, Tung E, Truong AQ, Look A, Giachelli CM: Role of carbonic anhydrase II in ectopic calcification. Cardiovasc Pathol 2009, 18:77-82

46. Blair HC: How the osteoclast degrades bone. Bioessays 1998, 20 : 837-846

47. Abedin M, Tintut Y, Demer LL: Vascular calcification: mechanisms and clinical ramifications. Arterioscler Thromb Vasc Biol 2004, 24:1161-1170

48. Mazzini MJ, Schulze PC: Proatherogenic pathways leading to vascular calcification. Eur J Radiol 2006, 57:384-389

49. van der Wal AC, Becker AE, Das PK: Medial thinning and atherosclerosis-evidence for involvement of a local inflammatory effect. Atherosclerosis 1993, 103:55-64
50. Yao PM, Tabas I: Free cholesterol loading of macrophages is associated with widespread mitochondrial dysfunction and activation of the mitochondrial apoptosis pathway. J Biol Chem 2001, 276:4246842476

51. Vengrenyuk Y, Carlier S, Xanthos S, Cardoso L, Ganatos P, Virmani R, Einav S, Gilchrist L, Weinbaum S: A hypothesis for vulnerable plaque rupture due to stress-induced debonding around cellular microcalcifications in thin fibrous caps, Proc Natl Acad Sci U S A 2006, 103 : 14678-14683

52. Ehara S, Kobayashi Y, Yoshiyama M, Shimada K, Shimada Y, Fukuda D, Nakamura $Y$, Yamashita H, Yamagishi H, Takeuchi K, Naruko T, Haze K, Becker AE, Yoshikawa J, Ueda M: Spotty calcification typifies the culprit plaque in patients with acute myocardial infarction: an intravascular ultrasound study. Circulation 2004, 110:3424-3429

53. Bengel FM: One life to live, but many ways to die-imaging of cardiomyocyte death. Eur J Nucl Med Mol Imaging 2006, 33:237-238

54. Gamble W: Atherosclerosis: the carbonic anhydrase, carbon dioxide, calcium concerted theory. J Theor Biol 2006, 239:16-21

55. Jacobin-Valat MJ, Deramchia K, Mornet S, Hagemeyer CE, Bonetto S, Robert R, Biran M, Massot P, Miraux S, Sanchez S, Bouzier-Sore AK, Franconi JM, Duguet E, Clofent-Sanchez G: MRI of inducible P-selectin expression in human activated platelets involved in the early stages of atherosclerosis, NMR Biomed 2010, 24:413-424 